\title{
Eriobotrya japonica Lindl. Kernels: Kinetics of Thermal Degradation under Inert Atmosphere Using Model-Free and Fitting Methods
}

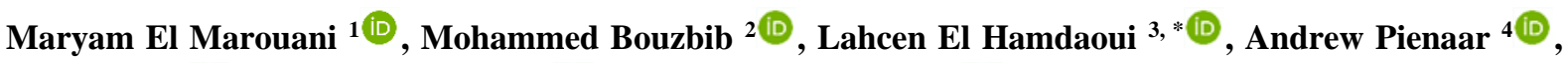 \\ Laszlo Trif ${ }^{5}$ (D) , Merlin Simo Tagne ${ }^{6}$ (i) , Fatima Kifani-Sahban ${ }^{7}$ (D)
}

1 Department of Chemistry, College of Sciences, University of Hafr Al Batin, Hafr Al Batin, kingdom of Saudi Arabia; melmarouani@uhb.edu.sa (M.E.);

2 ELTE Eötvös Loránd University, Institute of Chemistry, Pázmány Péter sétány 1/A., H-1117, Budapest, Hungary; m.bouzbib@gmail.com (M.B.);

3 Laboratory of Materials, Nanotechnology and Environment, Center of Materials Sciences, Faculty of Sciences, Mohammed V University in Rabat, Morocco; la.elhamdaoui@gmail.com (L.E.);

4 EPCM Global Engineering, Centurion, Republic of South Africa; a.pieaar@ gmail.com (A.P.);

5 Institute of Materials and Environmental Chemistry, Research Centre for Natural Sciences, Magyar tudósok körútja, 2, Hungary; trif.1@gmail.com (L.T.);

6 LERMab, ENSTIB, Epinal, France; m.siltagne@yahoo.fr (M.S.T);

7 Team of Modeling and Simulation of Mechanical and Energetic, Physical Department, Faculty of Sciences, Mohammed V University in Rabat, Morocco; kifani_sahban@yahoo.fr (F.K);

* Correspondence: la.elhamdaoui@gmail.com;

Scopus Author ID 57190738516

Received: 28.10.2020; Revised: 1.12.2020; Accepted: 4.12.2020; Published: 11.12.2020

Abstract: A kinetic study of the pyrolysis process of raw Eriobotrya japonica Lindl. Kernels (RLK) was investigated using a thermogravimetric analyzer. The weight loss was measured in a nitrogen atmosphere. The samples were heated over a range of temperature from $298 \mathrm{~K}$ to $873 \mathrm{~K}$ with four different heating rates of $5,10,15,20 \mathrm{~K} \mathrm{~min}^{-1}$. Mass loss (TGA) and derivative mass loss (DTG) measurements indicate that the increase in heating rate has no noticeable effect on the thermal degradation of the RLK. The results obtained from the thermal decomposition process indicate that there are three main stages such as dehydration, active, and passive pyrolysis. TGA curves indicate that active pyrolysis of RLK is between 160 and $450{ }^{\circ} \mathrm{C}$. In this interval, a shoulder followed by a peak exists on the DTG plots. The shoulder corresponds to the decomposition of hemicelluloses, the first peak to that of cellulose. Lignin decomposes through all temperature range. The kinetic parameters such as activation energy and pre-exponential factor were obtained for two degradation steps by isoconversional model-free methods proposed by FWO, KAS, Kissinger, Tang, MKN, and FR, with degradation mode being: $f(\alpha)=(1-\alpha) n$ with $n=1$ for FR and $g(\alpha)=-\operatorname{Ln}(1-\alpha)$ for the other methods. The activation energy and pre-exponential factor obtained by the Kissinger method are $173 \mathrm{~kJ} / \mathrm{mol}$ and $1.9 \times 1016 \mathrm{~min}^{-1}$. While for free model methods, the average kinetic parameters calculated are 172-248 $\mathrm{kJ} \mathrm{mol}^{-1}$ and 5,30×1020 for integral methods (FWO, KAS, Tang and MKN) and 190-271 kJ.mol ${ }^{-1}$ and $1.77 \times 1022 \mathrm{~min}^{-1}$ for differential Fr method. The activation energy decreases in the final stages of the process. The energy required for hemicellulose degradation is lower than that of cellulose. The most probable reaction functions have thus been determined for these two stages by Coats-Redfern and Criado method, leading to greatly improved calculation performance over the entire conversion range. The reaction, second-order F2, describes the pyrolysis reaction models of RLK. With the Arrhenius parameters obtained from the fitting model of CR, we attempt to reconstruct the temperature-dependent mass conversion curves and have resulted in generally acceptable results. Based on the Arrhenius parameter values obtained by Kissinger equation, the changes in entropy, enthalpy and Gibbs free 
energy, and lifetime predictions have been estimated concerning the thermal degradation processes of RLK.

Keywords: Raw Loquat Kernels (RLK); TG; DTA; DSC; kinetics; model free methods; model fitting methods.

(C) 2020 by the authors. This article is an open-access article distributed under the terms and conditions of the Creative Commons Attribution (CC BY) license (https://creativecommons.org/licenses/by/4.0/).

\section{Introduction}

Loquat (Eriobotrya japonica Lindl.) is a subtropical evergreen fruit tree native to China's southeast, belonging to the Maloideae subfamily of the Rosaceae. Loquat is cultivated in Cyprus, Egypt, Greece, Israel, Italy, Spain, Tunisia, and Turkey. It is also widely distributed in many European, Asian, and American countries [1,2]. Loquat was introduced and cultivated to Zegzel valley (Berkan, Marrakech, Fes-Meknes, Khemisset, and Tetouan) in Morocco in the sixties [3]. Indeed, under the Morocco Green Plan launched in recent years (PMV), loquat trees have benefited from subsidies for rehabilitation and densification of existing plantations and the creation of new modern ones [4]. This plan has led to an increase in the production of loquat fruit. Thus, according to the latest data [4], its total area is $270 \mathrm{Ha}$, and Production of 7,200 T with an average return of 20-25 T/Ha. With the increase in loquat fruit production, the amount of waste associated with the packaging and production of pulp and loquat juice, especially loquat kernels, rose significantly [4]. Although the loquats are small fruits of 3 to $5 \mathrm{~cm}$ in diameter, in the form of a spinning top, their flesh surrounds maximally four kernels, representing almost $90 \%$ of the fruit's total weight.

Based on the above consideration, loquat kernels are accordingly of significant economic interest, so their valuation is essential. Knowledge of raw kernels composition is therefore essential for any further application. Thus, loquat kernels contain extractable components with high added value. They are rich in protein, dietary fiber, phenolic compounds, and antioxidants [5].

Loquat kernels contain active components highly used in various fields, including medicine and cosmetics. One can find them to manufacture activated carbon [6] and bioadsorbents for dye removal [7, 8]. They are also substrates for bacterial [9] and methane fermentation [10]. Loquat kernels also contain many cyanide compounds, such as amygdalin, known for their anti-tumor efficacy. Indeed, in Asian countries, the loquat kernel powder was consumed for medicinal purposes, especially against cancer. It has been found that during its digestion, the cyanides contained in kernels turn into hydrocyanic acid toxic when decomposed in the human body. This is why the food and drug authorities have denied their use in traditional medicine. The amygdalin is extracted from loquat seeds. It is prescribed under medical supervision, yet, the effective therapeutic doses being established for the moment only in vivo [11]. However, loquat kernels are used in the food industries because they contain much starch [12].

However, even though loquat kernels have been the subject of several studies in recent years, as well as the fact that the presence of bioactive compounds in its composition has been proven, no reviews on loquat kernels kinetic data were found, and their energy features and valuation as fuel are still not sufficiently discussed. Therefore, we propose in this work to examine the thermal profile of loquat kernels to highlight their energy potential and the possibility of using them as fuel. 
The most emphasis on the use of biomass fuels, for environmental or economic reasons, demands a larger knowledge of kinetic parameters involved in the thermo-conversion reactions [13-16]. The kinetic investigation is one of the most important applications of thermal analysis, once the knowledge of the kinetic parameters, mechanisms, and mathematical models associated with the thermal decomposition process can take to the improvement of the current practices of biomass conversion, modeling of industrial processes, and combustion in furnaces and boilers [13-16].

Several methods can study degradation kinetics, but one of the most popular and simplest techniques widely used in the literature is the thermogravimetric analysis [17]. Literature reviews present several kinetic models related to biomass fuels' pyrolysis, e.g., the single reaction model, the consecutive reaction model, and the independent parallel model (IPR) [18].

This work aims to study the thermal features and degradation kinetics of the date seeds under an inert atmosphere through thermogravimetric analysis and differential thermal analysis. The kinetic parameters like $\mathrm{E}$ and $\ln \mathrm{A}$ were determined from the non-isothermal mass loss data using different temperature integral methods and the first-order reaction assumption. The performances of the isoconversional Friedman [19] Flynn-Wall-Ozawa method [20, 21], Kissinger-Akahira-Sunos [22,23], Coats-Redfern method [24], Madhusudanan-KrishnanNinan approximation method [25] Tang method [26] and Kissinger have been thoroughly compared. Based on the CR calculations, the most suitable reaction functions have been scanned to describe the two thermal pyrolysis stages of RLK. With the kinetic parameters of the activation energy $E$ and $\ln$ A of RLK, the changes in entropy, enthalpy and Gibbs free energy, and lifetime predictions have been made concerning the thermal degradation processes RLK.

\section{Materials and Methods}

\subsection{Materials.}

Fresh loquat (Eriobotrya japonica Lind1.) fruits were purchased from a local market in Berkane. Firstly, the seeds were manually removed from the flesh (edible parts) and other tissues. The seed testa or seed skin was separated from the kernel, and the loquat kernel was recovered. Kernels were cleaned once with distilled water to remove the undesirable materials, dried in the oven at $60^{\circ} \mathrm{C}$ for $24 \mathrm{~h}$. The seeds are then crushed using a micro-grinder and sieved, and the particle size used in this work is less than/or equal to $180 \mu \mathrm{m}$.

\subsection{Methods of material analyzes.}

\subsubsection{Proximate analysis.}

Proximate analysis of raw loquat kernels was performed according to AOAC (1995, 1997 and 000) [27-29]. Thus, the moisture content was measured gravimetrically by drying the sample in an air oven at $100^{\circ} \mathrm{C}$ until it reached a constant weight. Total nitrogen was determined by the Kjeldahl method (AOAC, 1997) [28], followed by the protein calculation using the general factor 6.25. Fat content was quantified by the Soxhlet method using ether as a solvent for 6 hours at $70^{\circ} \mathrm{C}$ and then removing the solvent by distillation. Ash was determined by combusting dry sample in a muffle furnace (Thermolyne 62700) at $525^{\circ} \mathrm{C}$ for around $18 \mathrm{~h}$. All 
values are expressed as mean $(n=3)$. Dry matter $(\mathrm{DM})$, organic matter $(\mathrm{OM})$, and total carbohydrates content are estimated using the following equations:

$$
\begin{gathered}
\mathrm{DM}=100 \text { - fat - Moisture } \\
\mathrm{OM}=100 \text { - Ashes }
\end{gathered}
$$

Total carbohydrates content $=100-[\%$ moisture $+\%$ protein $+\%$ fat $+\%$ Ash $]($ Weende method $)$ $\%$ lignin=OM- total carbohydrates content (Weende method)

The energy value was evaluated using the formula described by Egan et al. [30]

Energy $=(\%$ fat $\times 37 \mathrm{~kJ} / \mathrm{g})+(\%$ protein $\times 17 \mathrm{~kJ} / \mathrm{g})+(\%$ carbohydrate $\mathrm{x} 16 \mathrm{~kJ} / \mathrm{g})$

\subsubsection{Ultimate analyses and higher heating values HHV.}

The total elemental content of $\mathrm{C}, \mathrm{H}, \mathrm{N}$, and $\mathrm{S}$ in samples was measured on a CHNS analyzer (series II, PerkinElmer, USA). The percentage of oxygen content was then calculated using the following equation:

$$
\mathrm{O}(\%)=100-(\mathrm{C}+\mathrm{H}+\mathrm{N}+\mathrm{S}+\% \text { ash })
$$

The higher heating value (HHV) of the investigated sample was estimated using the ultimate analysis data; $\mathrm{C}, \mathrm{H}, \mathrm{O}$, and $\mathrm{N}$ contents; using the formula described by Ayhan Demirbas [31] $\mathrm{HHV}=\{33.5[\% \mathrm{C}]+142.3[\% \mathrm{H}]-15.4[\% \mathrm{O}]-14.5[\% \mathrm{~N}]\} \times 10-2(\mathrm{MJ} / \mathrm{kg})$

\subsubsection{Polysaccharides immunodetection.}

Samples were solubilized in ionic liquid acetate 1-ethyl-3-methylimidazole (EmimOAc) after 5 minutes of activation in the microwave at a maximum temperature below $80^{\circ} \mathrm{C}$ and a power of $200 \mathrm{~W}$. The solubilized polysaccharides are quantified via an antigenantibody reaction through an Enzyme-linked immunosorbent assay (ELISA) for rapid detection of polysaccharides, with a set of 14 monoclonal antibodies (mAbs) as described (Table1). The revelation was done in $50 \mu \mathrm{L}$ of 1-Step Ultra TMB (3.3',5,5'-Tetramethylbenzidine) - ELISA Substrate Solution (Life Technologies) for 20 min before being stopped by adding $50 \mu \mathrm{L}$ of $0.5 \mathrm{~N}$ sulfuric acids. Absorbance has been read at $450 \mathrm{~nm}$ and $655 \mathrm{~nm}$ with a microplate reader (BMG-Labtech, FLUOstar Omega) (reference: Plazanet I, et al. Ann Glycomics Lipidomics: AGL-101 DOI: 10.29011/AGL-101/100001) [32].

\subsubsection{X-ray diffraction.}

The powder diagram of raw loquat kernels is recorded with a diffractometer Siemens D5000 type using $\mathrm{K} \alpha_{1}$ ray of copper $(\lambda=1.5406 \AA$ ).

The degree of relative crystallinity was quantitatively estimated, following the method described in the literature [33]. A smooth curve, with connecting peak baselines, was computed and plotted on the diffractograms. The area above the smooth curve was taken as the crystalline portion. The lower area between the smooth curve and the linear baseline covering the $2 \mathrm{~h}$ range from 5 to 50 was taken as the amorphous section. The upper diffraction peak area and the total diffraction area over the diffraction angle 5-50 were integrated. The ratio of upper area to total diffraction was used as the degree of relative crystallinity. The equation for calculating the degree of relative crystallinity is as follows:

$$
X_{c}=\frac{A_{p}}{A_{b}}+A_{b}
$$

Where, Xc refers to the degree of relative crystallinity, Ap refers to the crystallized area on the $\mathrm{X}$-ray diffractogram, and $\mathrm{Ab}$ refers to the amorphous area on the X-ray diffractogram [33]. 
2.2.5. Thermogravimetric and differential thermal analyzes.

The thermogravimetric (TG) and thermal differential analyzes (DTA) of loquat kernels were made on a simultaneous thermal analyzer of the 'LabsysTMEvo (1F)' type and SETARAM brand. This device consists of a TG microbalance associated with DTA sensor with a single rod, a metal resistor furnace up to $1600^{\circ} \mathrm{C}$, and multitasking software controlling the various modules. The tests are carried out from ambient temperature to $600^{\circ} \mathrm{C}$ at four heating rates $\left(5,10,15\right.$, and $\left.20^{\circ} \mathrm{C} / \mathrm{min}\right)$ under nitrogen with a $10 \mathrm{~cm} 3 / \mathrm{min}$ flow rate. The initial mass of samples is about $10 \mathrm{mg}$, and the particle size is of $180 \mu \mathrm{m}$. Three replicates were used for thermogravimetric and thermal differential analyzes.

\subsubsection{Differential scanning calorimetry.}

The differential scanning calorimetry (DSC) measurements are carried out on a SETARAM DSC 12 type apparatus. The tests are carried out from ambient temperature to $500{ }^{\circ} \mathrm{C}$, under argon with a flow rate of $10 \mathrm{~cm}^{3}$ and a temperature rise rate of $5^{\circ} \mathrm{C} \cdot \mathrm{min}^{-1}$. The sample's initial mass is about $10 \mathrm{mg}$, and the particle size of the order of $180 \mu \mathrm{m}$.

\subsection{Kinetic approach.}

\subsubsection{Theoretical background.}

The kinetics of solid reactions are described by various explicitly analytical equations considering their decomposition reactions' special features. The reaction rate for a solid reaction may be represented through the degree of conversion, $\alpha$, according to the formula as follows:

$$
\alpha=\frac{m_{0}-m_{t}}{m_{0}-m_{f}}
$$

Where, $\mathrm{m}_{\mathrm{t}}, \mathrm{m}_{0}$, and $\mathrm{m}_{\mathrm{f}}$ are, respectively, the mass at time $\mathrm{t}$, initial mass, and final mass of the sample. They are all collected from experimental mass loss results. Then, the kinetic equation of the reaction process can be generalized as the following:

$$
\frac{d \alpha}{d t}=k(T) f(\alpha)
$$

Where, $\mathrm{d} \alpha / \mathrm{dt}$ is the mass conversion rate, $\mathrm{T}$ is the absolute temperature $(\mathrm{K}), \mathrm{k}(\mathrm{T})$ is the degradation rate constant, and $f(\alpha)$ is the differential form of a kinetic model function. For very common non-isothermal measurements, the sample was heated at a constant rate of $b$. Then, $\beta$ $=\mathrm{dT} / \mathrm{dt}=$ constant. The temperature dependence of the rate constant $\mathrm{k}(\mathrm{T})$ is usually described by the Arrhenius equation:

$$
k(T)=A \exp \left(\frac{-E_{a}}{R T}\right)
$$

Where, $\mathrm{E}$ is the apparent activation energy, $\mathrm{A}$ is the pre-exponential factor, and $\mathrm{R}$ is the gas constant. Substitution of Eq. 3 in Eq. 2 gives:

$$
\frac{d \alpha}{d t}=A f(\alpha) \exp \left(\frac{-E}{R T}\right)
$$

For a specific solid-state reaction, the expression of $f(\alpha)$ depends on the reaction mechanism. 
The expression of the function $\mathrm{f}(\alpha)$ and its derivative is used for describing solid-state first order reaction; hence many authors restrict the mathematical function $f(\alpha)$ to the following expression:

$$
\mathrm{f}(\alpha)=(1-\alpha)^{\mathrm{n}}
$$

Where, $\mathrm{n}$ is the reaction order, substituting expression (5) into equation (4) gives the expression of reaction rate in the form:

$$
\frac{d \alpha}{d t}=A(1-\alpha)^{n} \exp \left(\frac{-E_{a}}{R T}\right)
$$

For non-isothermal TGA experiments at linear heating rate $\beta=\mathrm{dT} / \mathrm{dt}$, equation (6) can be written as:

$$
\frac{d \alpha}{d t}=\frac{A}{\beta}(1-\alpha)^{n} \exp \left(\frac{-E_{a}}{R T}\right)
$$

This equation expresses the fraction of material consumed in the time.

After separating variables and integrating, taking into account the variation of the temperature as a function of time, Eq. (4) may be transformed as:

$$
\mathrm{g}(\alpha)=\int_{0}^{\alpha} \frac{\mathrm{d} \alpha}{\mathrm{f}(\alpha)}=\frac{\mathrm{A}}{\beta} \int_{\mathrm{T}_{0}}^{\mathrm{T}} \exp \left(-\frac{\mathrm{E}_{\mathrm{a}}}{\mathrm{RT}}\right) \mathrm{dT}
$$

Where, $g(\alpha)$ is the integral form of the reaction model function. The right-hand side of Eq. (8) is a well-known temperature integral function that has no analytical solution but can be determined by using either numerical methods or approximations. The latter has been considered in this paper for kinetic analysis.

In this work, the activation energy was obtained from non-isothermal TGA. The methods used to calculate kinetic parameters are called model-free non-isothermal methods and require a set of experimental tests at different heating rates.

\subsubsection{Isoconversional kinetic analysis methods.}

ICTAC kinetics committee recommends model-free isoconversional methodology used for kinetically analyzing non-isothermal experiments since model-free methods are believed to be the most reliable methods for calculating the activation energy of thermally activated reactions [34]. Model-free methods can calculate the activation energy, Ea, at progressive conversion values, $\alpha$, without any modelistic assumptions. Using isoconversional methods, the activation energy at a given degree of conversion does not depend on the heating rate. At present, isoconversional methods based on multiple heating programs are the most popular method that can unscramble the kinetics of thermal decomposition reactions.

\subsubsection{Friedman method.}

Friedman [19] was the first to apply the differential method to mass loss paths obtained at different heating rates; he used the equation (6) in the following form:

$$
\operatorname{Ln} \frac{\mathrm{d} \alpha}{\mathrm{dt}}=\operatorname{Ln}[\operatorname{Af}(\alpha)]-\frac{\mathrm{Ea}}{\mathrm{RT}}
$$

This method allows the value of activation energy from a plot of $\ln (\mathrm{d} \alpha / \mathrm{dt})$ against $1000 / \mathrm{T}$ for a series of experiments at different heating rates $(\beta)$. 


\subsubsection{Kissinger method.}

These methods allow obtaining the kinetic parameters of a solid-state reaction without knowing the reaction mechanism. Kissinger [22] developed a model-free non-isothermal method with no need to calculate Ea for each conversion value to evaluate kinetic parameters. This method allows the obtaining the value of activation energy from a plot of $\ln \left(\beta / \mathrm{Tm}^{2}\right)$ against $1000 / \mathrm{T}$ for a series of experiments at different heating rates $(\beta)$, where, $\mathrm{Tm}$ is the temperature peak of the DTG curve (shown in Fig. 6). The equation is the following:

$$
\operatorname{Ln}\left(\frac{\beta}{T_{m}^{2}}\right)=\operatorname{Ln}\left(\frac{A R}{E_{a}}\right)-\frac{E_{a}}{R T_{m}}
$$

\subsubsection{Flynn-Wall-Ozawa method.}

The FWO method [20, 21] allows the obtaining apparent activation energy (Ea) from a plot of the natural logarithm of heating rates, $\ln \beta$, versus $1000 / T$, which represents the linear relation with a given value of conversion at different heating rates.

$$
\operatorname{Ln} \beta_{\mathrm{i}}=\operatorname{Ln}\left(\frac{\mathrm{A} \mathrm{E} \mathrm{E}_{\mathrm{a}}}{\mathrm{Rg}(\alpha)}\right)-5,331-1,052 \frac{\mathrm{E}_{\mathrm{a}}}{\mathrm{R} \mathrm{T}_{\alpha, \mathrm{i}}}
$$

Where, $g(\alpha)$ is constant at a given value of conversion, the subscripts $i$ and $\alpha$ denote the given value of the heating rate and the given value of a conversion. The activation energy Ea is calculated from the slope $-1.052 \mathrm{E}_{\mathrm{a}} / \mathrm{R}$.

Once the integral reaction function $\mathrm{g}(\alpha)$ is correctly known, the pre-exponential factor ln A can be simply determined from the above expression.

Initially, the first-order reaction with $g(\alpha)=-\ln (1-\alpha)$ has been adopted for kinetic analysis of RLK thermal degradation.

\subsubsection{Madhusudanan-Krishnan-Ninan method.}

Later, Madhusudanan et al. [25] have proposed three different new approximate formulae for integral temperature calculation. Of these approximations, the one given below performs the best and is denoted as the present study's MKN method.

$$
\operatorname{Ln}\left[\frac{\beta}{\mathrm{T}^{1.884318}}\right]=\operatorname{Ln}\left[\frac{\mathrm{A}}{\mathrm{g}(\alpha)}\left(\frac{\mathrm{Ea}}{\mathrm{R}}\right)^{-0.884318}\right]-1.0011928 \frac{\mathrm{Ea}}{\mathrm{RT}}-0.389677
$$

Apparently, a straight line could be yielded for each conversion $\alpha$ if plotting $\operatorname{Ln}\left[\beta / T^{1.884318}\right]$ against $1 / \mathrm{T}$. Readily, Ea and A's values can be, respectively, calculated from the slope and intercept terms, provided that a reaction function $g(\alpha)$ is explicitly given.

\subsubsection{Tang method.}

Similarly, Tang et al. [26] have attempted the numerical analysis to boost the integral temperature approximation accuracy and put forward a newly modified form to the MKN method with relatively improved accuracy and reliability. This approximation, denoted as the Tang method, can be expressed as below:

$$
\operatorname{Ln}\left[\frac{\beta}{\mathrm{T}^{1.894661}}\right]=\operatorname{Ln}\left[\frac{\mathrm{A}}{\mathrm{g}(\alpha)}\left(\frac{\mathrm{Ea}}{\mathrm{R}}\right)^{-0.894661}\right]-1.00145033 \frac{\mathrm{Ea}}{\mathrm{RT}}-0.37773896
$$

Accordingly, the plots of $\operatorname{Ln}[\beta / \mathrm{T} 1.894661]$ against $1 / \mathrm{T}$ should result in a straight line for each chosen conversion, 
and the values of $\alpha$ series of Ea can be calculated from the slopes of the resultant lines. Similarly, the A cannot be obtained from the intercepts if the $g(\alpha)$ is not scanned correctly.

\subsubsection{Coats-Redfern method.}

Coats-Redfern method [24] is also an integral method, and it involves the thermal degradation mechanism. Using an asymptotic approximation for the resolution of Eq. (8) $(2 \mathrm{RT} / \mathrm{Ea}<<1)$, the following equation can be obtained:

$$
\operatorname{Ln}\left(\frac{\mathrm{g}(\alpha)}{\mathrm{T}^{2}}\right)=\operatorname{Ln} \frac{\mathrm{AR}}{\beta \mathrm{Ea}}-\frac{\mathrm{Ea}}{\mathrm{RT}}
$$

With the kinetic parameters calculated, the thermal degradation curves could be reconstructed for evaluating the calculation performance.

\subsubsection{Criado method.}

If the activation energy value is known, the process's kinetic model can be determined by Criado method [35] method. Combining Eq. (4) with Eq. (14), the following equation is obtained:

$$
\frac{\mathrm{Z}(\mathrm{x})}{\mathrm{Z}(0.5)}=\frac{\mathrm{f}(\alpha) \mathrm{g}(\alpha)}{\mathrm{f}(0.5) \mathrm{g}(0.5)}=\left(\frac{\mathrm{T}_{\mathrm{x}}}{\mathrm{T}_{0.5}}\right)^{2} \frac{(\mathrm{dx} / \mathrm{dt})_{\mathrm{x}}}{(\mathrm{dx} / \mathrm{dt})_{0.5}}
$$

Where, 0.5 refers to the conversion in $x=0.5$.

The left side of Eq. (15) $f(x) g(x) / f(0.5) g(0.5)$ is a reduced theoretical curve, which is characteristic of each reaction mechanism. In contrast, the equation's right side associated with the reduced rate can be obtained from experimental data.

\begin{tabular}{|c|c|c|c|}
\hline Degradation mode & Code & Differential form : $f(\alpha)$ & Integral form : $g(\alpha)$ \\
\hline \multicolumn{4}{|l|}{ Diffusion } \\
\hline One-way transport & D1 & $1 /(2 \alpha)$ & $\alpha^{2}$ \\
\hline two-way transport, Valensi-Barrer & D2 & $-1 / \operatorname{Ln}(1-\alpha)$ & $\alpha+(1-\alpha) \operatorname{Ln}(1-\alpha)$ \\
\hline three-way transport, Jander & D3 & $1,5(1-\alpha)^{2 / 3} /\left[1-(1-\alpha)^{1 / 3}\right]$ & {$\left[1-(1-\alpha)^{1 / 3}\right]^{2}$} \\
\hline Ginstling-Brounshtein & D4 & $1,5 /\left[(1-\alpha)^{-1 / 3}-1\right]$ & $1-2 \alpha / 3-(1-\alpha)^{2 / 3}$ \\
\hline Zhuravlev & D5 & $1,5(1-\alpha)^{2 / 3} /\left[1 /(1-\alpha)^{1 / 3}-1\right]$ & {$\left[1 /(1-\alpha)^{1 / 3}-1\right]^{2}$} \\
\hline Anti-Jander & D6 & $1,5(1+\alpha)^{2 / 3} /\left[(1+\alpha)^{1 / 3}-1\right]$ & {$\left[(1+\alpha)^{1 / 3}-1\right]^{2}$} \\
\hline Kroger-Ziegler & D7 & {$\left[1,5(1-\alpha)^{2 / 3} /\left[1-(1-\alpha)^{1 / 3}\right]\right] / t$} & $\left.\left[1-(1-\alpha)^{1 / 3}\right)\right]^{2}-\log (t)$ \\
\hline Two dimensions, Jander & D8 & $(1-\alpha)^{1 / 2} /\left[1-(1-\alpha)^{1 / 2}\right]$ & $\left.\left[1-(1-\alpha)^{1 / 2}\right)\right]^{2}$ \\
\hline Two dimensions, Anti-Jander & D9 & $(1+\alpha)^{1 / 2} /\left[(1+\alpha)^{1 / 2}-1\right]$ & {$\left[(1+\alpha)^{1 / 2}-1\right]^{2}$} \\
\hline Interfacial transfer & D10 & $3(1-\alpha)^{4 / 3}$ & {$\left[1 /(1-\alpha)^{1 / 3}-1\right]$} \\
\hline Transfer and diffusion & D11 & $3 /\left[(1-\alpha)^{-4 / 3}-(1-\alpha)^{-1}\right]$ & $1 /(1-\alpha)^{1 / 3}-1+1 / 3 \operatorname{Ln}(1-\alpha)$ \\
\hline Diffusion with two directions & D12 & $3 /\left[(1-\alpha)^{-8 / 3}-(1-\alpha)^{-7 / 3}\right]$ & $1 / 5(1-\alpha)^{-5 / 3}-1 / 4(1-\alpha)^{-4 / 3}+1 / 20$ \\
\hline \multicolumn{4}{|l|}{ Random nucleation and nuclei growth } \\
\hline $\begin{array}{l}\text { Avrami-Erofeev } \\
\mathrm{n}=1,2,3,4 \text { et } 5\end{array}$ & An & $\begin{array}{c}x(1-\alpha)[-\operatorname{Ln}(1-\alpha)]^{y} \\
x=4,2,3,4 / 3 \text { and } 3 / 2 \\
y=3 / 4,1 / 2,2 / 3,1 / 4 \text { and } 1 / 3\end{array}$ & $\begin{array}{c}{[-\operatorname{Ln}(1-\alpha)]^{z}} \\
z=1 / 4,1 / 2,1 / 3,3 / 4 \text { and } 2 / 3\end{array}$ \\
\hline \multicolumn{4}{|l|}{ Chemical reactions } \\
\hline Zero order & F0 & Constant & $\alpha$ \\
\hline First order & F1 & $1-\alpha$ & $-\operatorname{Ln}(1-\alpha)$ \\
\hline Second order & F2 & $(1-\alpha)^{2}$ & $(1-\alpha)^{-1}-1$ \\
\hline $\begin{array}{l}\text { Contraction (surface, volume and interface } \\
\text { respectively for } n=2,3 \text { and } 4 \text { ) }\end{array}$ & $\mathbf{R n}$ & $\begin{array}{c}x(1-\alpha)^{y} \\
x=2,3 \text { et } 3 / 2 \cdot y=1 / 2,2 / 3 \text { and } 1 / 3\end{array}$ & $\begin{array}{c}1-(1-\alpha)^{\mathrm{z}} \\
\mathrm{z}=1 / 2,1 / 3 \text { and } 2 / 3\end{array}$ \\
\hline \multicolumn{4}{|l|}{ Power / Exponential } \\
\hline $\begin{array}{l}\text { Low power (half, third and quarter } \\
\text { respectively for } n=2,3 \text { and } 4 \text { ) }\end{array}$ & Pn & $\begin{array}{c}n \alpha^{\mathrm{x}} \\
\mathrm{x}=1 / 2,2 / 3 \text { and } 3 / 4\end{array}$ & $\begin{array}{c}\alpha^{y} \\
y=1 / 2,1 / 3 \text { et } 1 / 4\end{array}$ \\
\hline Exponential & E1 & $\alpha$ & $\operatorname{Ln}(\alpha)$ \\
\hline
\end{tabular}

Table 1. Algebraic expressions of functions of the most common reaction mechanisms.

$\mathrm{D}_{1}, \mathrm{D}_{2}, \ldots$. are symbols given to models 
A comparison of both sides of Eq. (15) tells us which kinetic model describes an experimental reactive process. Table 1 indicates the algebraic expressions of $f(x)$ and $g(x)$ for the kinetic models used.

\subsection{Calculation of thermodynamic parameters.}

Based on the transition state theory, the rate of constant expression can be given as the well-known Eyring equation of the activated complex [36, 37]:

$$
\mathrm{K}=\frac{\chi \mathrm{ek}_{\mathrm{B}} \mathrm{T}_{\mathrm{p}}}{\mathrm{h}} \exp \left(\frac{\Delta \mathrm{S}^{\#}}{\mathrm{R}}\right) \exp \left(-\frac{\mathrm{E}_{\mathrm{a}}}{\mathrm{RT}}\right)
$$

Where, $\chi$ is the transmission coefficient, which is unity for monomolecular reactions, $k_{\mathrm{B}}$ is Boltzmann's constant, $h$ is

Planck's constant and e $=2.7183$ is Neper's number, and $\mathrm{T}_{\mathrm{p}}$ is the average peak temperature of the DTG curves at different heating rates.

Taking into account that :

$$
\mathrm{A}=\frac{\chi \mathrm{ek}_{\mathrm{B}} \mathrm{T}_{\mathrm{p}}}{\mathrm{h}} \exp \left(\frac{\Delta \mathrm{S}^{\#}}{\mathrm{R}}\right)
$$

The thermodynamic functions $\Delta \mathrm{S}^{\#}, \Delta \mathrm{H}^{\#}$, and $\Delta \mathrm{G}^{\#,}$ which well characterize the decomposition process, may be calculated. Then, the change of the entropy could also be calculated according to the formula:

$$
\Delta \mathrm{S}^{\#}=\mathrm{R} \operatorname{Ln} \frac{\mathrm{Ah}}{\chi \mathrm{ek}_{\mathrm{B}} \mathrm{T}_{\mathrm{p}}}
$$

Since

$$
\Delta \mathrm{H}^{\#}=\mathrm{E}_{\mathrm{a}}-\mathrm{RT}_{\mathrm{p}}
$$

The changes of Gibbs free energy $\Delta \mathrm{G} \#$ for the activated complex formation from the reagents can be calculated using the well-known thermodynamic equation:

$$
\Delta \mathrm{G}^{\#}=\Delta \mathrm{H}^{\#}-\mathrm{T}_{\mathrm{p}} \Delta \mathrm{S}^{\#}
$$

The values of $\Delta \mathrm{S}^{\#}, \Delta \mathrm{H}^{\#,}$ and $\Delta \mathrm{G}^{\#}$ were calculated at $\mathrm{T}=\mathrm{Tp}$, since this temperature characterizes the process's highest rate.

Based on the results of Ea and A calculated from the Kissinger equation over the whole RLK decomposition, $\Delta \mathrm{G}^{\#}, \Delta \mathrm{H}^{\#,}$ and $\Delta \mathrm{S}^{\#}$ can be obtained to form the activated complex from the reagent and the calculated results are presented in Table 6.

\subsection{Estimation of a lifetime.}

Lifespan estimation helps select polymers for different specific applications properly, and the accelerated air oven aging studies may determine it; however, this kind of method usually takes very long periods for materials lifespan measurements. For practical applications, the service life is a critical parameter to various polymer-based articles. Usually, polymer materials' physical properties will decrease considerably and fail to service properly when their mass loss approaches a certain amount. In this work, the life period of RLK, $\mathrm{t}_{\mathrm{p}}$, has been estimated as the time when its mass loss reaches $5 \%$, i.e., $\mathrm{a}=0.05$, and can be estimated by using the following equation:

$$
\mathrm{t}_{\mathrm{p}}=\frac{0.0513}{\mathrm{~A}_{\mathrm{p}}} \exp \left(\frac{\mathrm{E}_{\mathrm{p}}}{\mathrm{RT}}\right)
$$


Where, Ep is the activation energy and usually evaluated from Kissinger's plot and $A_{p}$ is the pre-exponential factor evaluated as follows:

$$
\mathrm{A}_{\mathrm{p}}=\frac{\beta \mathrm{E}_{\mathrm{p}}}{\mathrm{RT}_{\mathrm{p}}} \exp \left(\frac{\mathrm{E}_{\mathrm{p}}}{\mathrm{RT}_{\mathrm{p}}}\right)
$$

With these prerequisite assumptions, the time to undergo equivalent thermal damage at different temperatures or the time to various damages under isothermal conditions can be readily estimated. It should be noted that the method used here is very rough and may lead to high errors in lifetime predictions. However, the estimation does provide certain information for subsequent thermal applications.

\section{Results and Discussion}

\subsection{Raw loquat kernels composition.}

The Proximate analysis of raw loquat kernels and energy value expressed in (Kcal/100g) are gathered in table 2.

Table 2. Proximate analysis of raw loquat kernels (\%) and energy value (Kcal/100g).

\begin{tabular}{l|l} 
Moisture & 9.73 \\
\hline Ash & 1.60 \\
\hline Crude fat & 4.10 \\
\hline Crude protein & 7.92 \\
\hline DM & 87.17 \\
\hline OM & 97.1 \\
\hline total carbohydrates & 71.43 \\
\hline Lignin & 13.32 \\
\hline Energy & 341.53
\end{tabular}

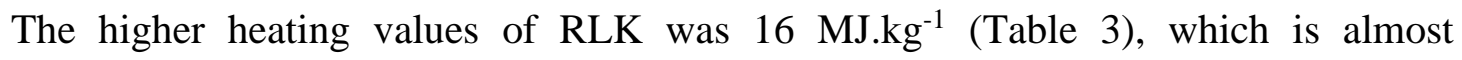
comparable to the energy content of multiple agricultural byproducts such as rapeseed straw (17.64 MJ.kg-1) [38], pine chips (18.98 MJ.kg-1) [39], and Hardwood (19.10 MJ.kg-1) [40, 41]. Softwood [42] presents higher heating values compared to other biomass types. For the same biomass, Sütcü et al. [6] have recorded quite a similar value, $16.95 \mathrm{MJ} . \mathrm{kg}^{-1}$.

Table. 3. Ultimate composition (wt \% dry basis) and HHV (kcal/kg) (dry basis) of RLK.

\begin{tabular}{|c|c|c|c|c|c|c|}
\hline Sample & \multicolumn{5}{|c|}{ Ultimate analysis (wt\% dry basis) } & HHV (MJ /kg) (dry basis) \\
\hline \multirow{2}{*}{ RLK } & $\% \mathrm{C}$ & $\% \mathrm{H}$ & $\% \mathrm{~N}$ & $\% \mathrm{O}$ & $\% S$ & \multirow{2}{*}{16} \\
\hline & 43.60 & 6.27 & 0.46 & 47.95 & 0.12 & \\
\hline \multirow{2}{*}{ RLK [6] } & $\% \mathrm{C}$ & $\% \mathrm{H}$ & $\% \mathrm{~N}$ & $\% \mathrm{O}$ & $\% \mathrm{~S}$ & \multirow{2}{*}{16.95} \\
\hline & 42.38 & 6.60 & 0.58 & 47.82 & 0.084 & \\
\hline \multirow{2}{*}{ Hardwood [41] } & $\% \mathrm{C}$ & $\% \mathrm{H}$ & $\% \mathrm{~N}$ & $\% \mathrm{O}$ & $\% \mathrm{~S}$ & \multirow{2}{*}{17} \\
\hline & 48.2 & 5.6 & 0.9 & 45.3 & - & \\
\hline \multirow{2}{*}{ Softwood [42] } & $\% \mathrm{C}$ & $\% \mathrm{H}$ & $\% \mathrm{~N}$ & $\% \mathrm{O}$ & $\% \mathrm{~S}$ & \multirow{2}{*}{24} \\
\hline & 47 & 7.7 & 0.1 & 45.2 & - & \\
\hline
\end{tabular}

Polysaccharide immuno-detection (figure 1) [32] highlights important amounts of unesterified Homogalacturonans and xyloglucans, with traces of Mannanes and Galactanes and complete absence of Arabinanes and Xylanes among loquat seeds polysaccharides.

Quantities of RLK dissolved: $10 \mu \mathrm{g}$ for CCRC-M14, LM19, LM25, 5 $\mu \mathrm{g}$ for LM5, and $0.5 \mu \mathrm{g}$ for LM11 and LM21 (Table 4). Dissolution and ELISA were done in triplicate. 


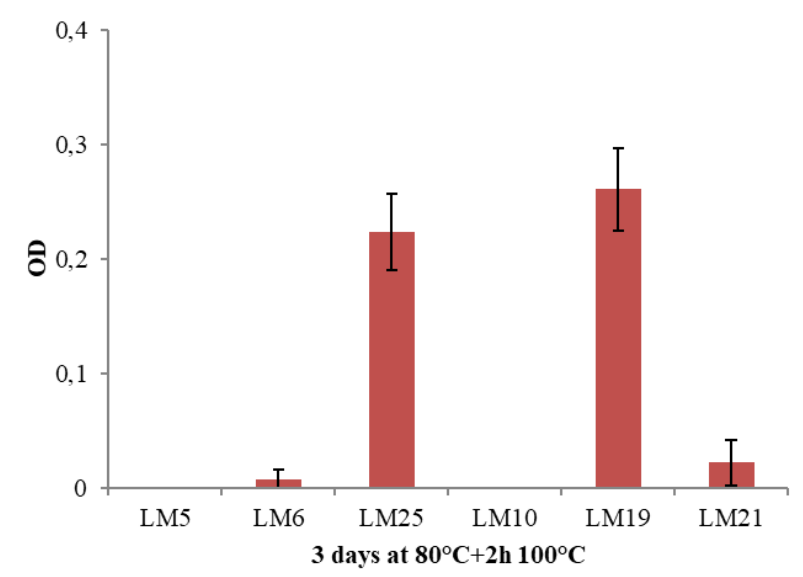

Figure 1. Immuno-labeling intensity (OD) measurement for a set of 6 antibodies in the function of time and temperature after RLK polysaccharide dissolution in [Emim]Br.

Table 4. Monoclonal list of antibodies (mAbs).

\begin{tabular}{l|l} 
Antibody & Polymers recognition \\
\hline LM21 & Mannan, glucomannan, galactomannan \\
\hline LM10 & Un-substituted xylan, low substituted arabinoxylan \\
\hline LM25 & Xyloglucan, XLLG, XXLG, XXXG \\
\hline LM5 & Galactan \\
\hline LM19 & Un-esterified Homogalacturonan \\
\hline LM6 & Arabinan
\end{tabular}

Antibody: name code of the antibody,

Polymer recognition: epitope or polysaccharide recognized by the antibody.

X-ray diffraction patterns of raw loquat kernels are given in Fig. 2. The diffractogram does not exhibit a basic horizontal line. This shows that the major part of the matter is amorphous. However, a few diffraction peaks emerge from the basic line, indicating a small amount of crystalline matter.

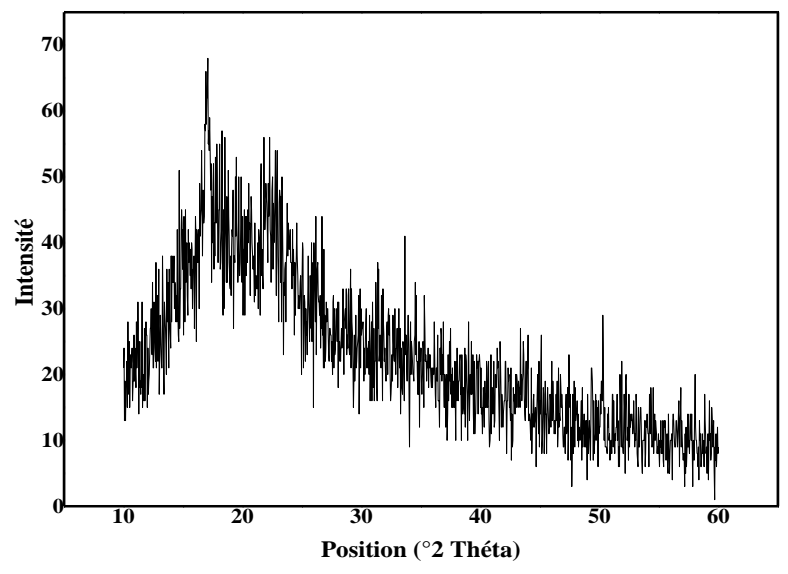

Figure 2. X-ray diffraction patterns of loquat kernels.

Table 5. Bragg diffraction angle $\left({ }^{\circ} 2 \mathrm{Th}\right)$ and reticular distance $(\mathrm{d})$ of RLK and their corresponding compounds identified in the JCPDF crystallographic database.

\begin{tabular}{l|l|l} 
Pos. $\left[{ }^{\circ} \mathbf{2} \theta\right]$ & $\mathbf{d}(\mathbf{\AA})$ & Corresponding compounds \\
\hline 18.4921 & 5.57122 & N.Cel et HCel \\
\hline 22.9887 & 4.49214 & N.Cel et HCel \\
\hline 27.4209 & 3.77678 & C \\
\hline 30.8246 & 3.36824 & HCel \\
\hline 38.5353 & 2.71274 & N.Cel et HCel \\
(N.Cl : native cellulose, HCel: hemicellulose dehydrate, C: solid carbon)
\end{tabular}

(N.Cl : native cellulose, HCel: hemicellulose dehydrate, C: solid carbon) 
The XRD pattern of RLK has been compared to those of native cellulose $\left(\mathrm{C}_{6} \mathrm{H}_{12} \mathrm{O}_{6}\right)$, xylane dehydrate $\left(\mathrm{C}_{10} \mathrm{H}_{12} \mathrm{O}_{9.2} \mathrm{H}_{2} \mathrm{O}\right)$, or hemicellulose dehydrates given in the JCPDF crystallographic database (Table 5).

The XRD results show that RLK had relative crystallinity of $24.43 \%$, similar to results obtained by Barbi et al. [12].

The composition mentioned above characterizations is typically by most of the biomass contents used for pyrolysis purposes [43-46].

\subsection{Thermogravimetric analysis.}

Figure 3 shows the TG/DTG curves that are mass loss of RLK as a function of temperature at four heating rates $\left(5,10,15\right.$, and $\left.20^{\circ} \mathrm{C} / \mathrm{min}\right)$. Table 6 gather data taken from TG/DTG curves of RLK under nitrogen atmosphere at different heating rates.

The TG curves highlight two thermal decomposition zones, the first one with a loss of approximately $12 \%$ and the second with a loss of $55 \%$. The first range, from room temperature to about $130^{\circ} \mathrm{C}$, with a maximum peak around $90^{\circ} \mathrm{C}$ on the derivative curve, is relative to dehydration. This latter would be linked to the departure of the so-called free water of the material retained in vessels and fiber lumens [47]. Other volatile compounds may also leave the material as specified by some work [48].

The second zone, from 130 to $410{ }^{\circ} \mathrm{C}$, corresponds to the main pyrolysis. The loss of mass $55 \%$ represents the volatile, condensable, and non-condensable matters emitted by the decomposition of the vegetable matter. At the end of the thermal solicitation, the yield of solid residue, in this case, loquat kernels char, is around $25 \%$ at $500{ }^{\circ} \mathrm{C}$.

The changes in the slope of TG curves in the temperature range between 130 and 410 ${ }^{\circ} \mathrm{C}$ indicate the decomposition of the different constituents of loquat kernels, which are hemicelluloses, cellulose, and lignin. The plot of the mass loss and that of the mass loss derivative leads us to distinguish three groups of constituents and their decomposition intervals. Thus, between 130 and $230{ }^{\circ} \mathrm{C}$, the mass loss is of about $12 \%$, on the derivative curve DTG, there corresponds a shoulder to $220^{\circ} \mathrm{C}$, between 230 and $320^{\circ} \mathrm{C}$ the loss is of $35 \%$, on DTG curve, there corresponds a thin and strong peak at $300^{\circ} \mathrm{C}$, and from 320 to $410^{\circ} \mathrm{C}$ the loss is of $12 \%$. The literature on the thermal decomposition of vegetable matters [49-51] and that of loquat kernels [6] makes possible to attribute the first mass loss to the release of so-called, bounded, hygroscopic or constitution water retained by cell walls, and considered as adsorbed on hydroxyl functions of polysaccharides chains and lignin mainly by van der Waals and on the other hand, to the irreversible destruction of hemicelluloses and cellulose (holocellulose) $[52,53]$. It was also considered by certain authors [54] that between 180 and $280{ }^{\circ} \mathrm{C}$, pyrolysis is in the torrefaction zone, where the solid residue has lost its ability to regain moisture. The second and the last mass loss are related to cellulose is the lignin thermal decomposition [52]. This latter decomposes at low temperatures, and its degradation continues as long as the thermal solicitation is maintained [53, 54]. 

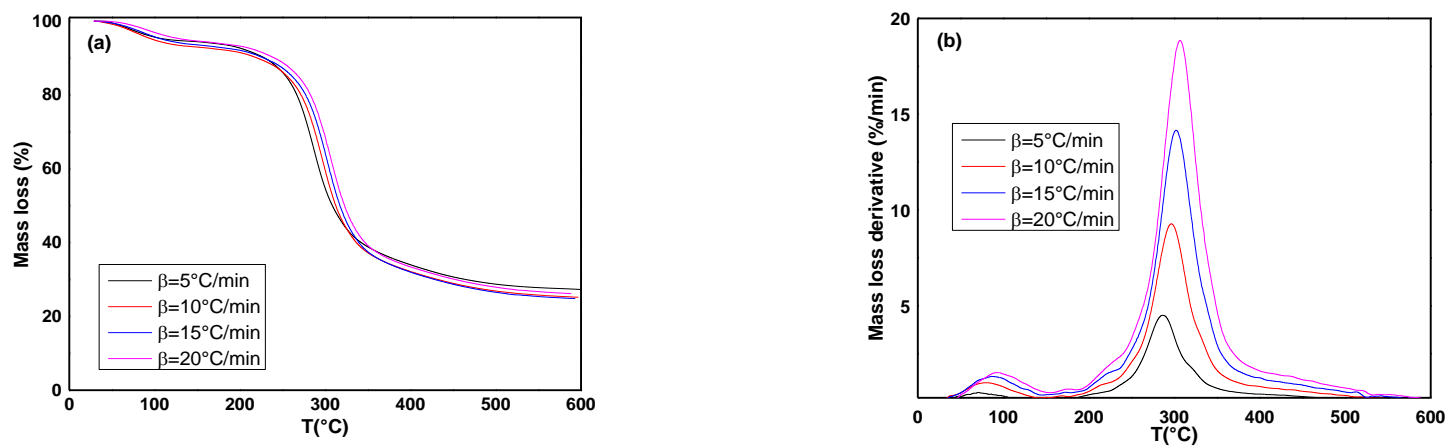

Figure 3. TG (a) and DTG (b) plots of loquat kernels.

Table 6. Data were taken from TG/DTG curves of RLK under nitrogen atmosphere at different heating rates

\begin{tabular}{|c|c|c|c|}
\hline Heating rate & $\begin{array}{l}\text { Temperature } \\
\text { range }\left({ }^{\circ} \mathrm{C}\right)\end{array}$ & $\begin{array}{l}\text { Mass loss } \\
\text { or residue (\%) }\end{array}$ & $\begin{array}{l}\text { DTG } \\
\text { maxima }\left({ }^{\circ} \mathrm{C}\right)\end{array}$ \\
\hline \multirow{4}{*}{$\beta=5^{\circ} \mathrm{C} / \mathrm{min}$} & $108-205$ & 5.23 & \multirow{4}{*}{286.7} \\
\hline & $205-305$ & 35.21 & \\
\hline & $305-360$ & 12.20 & \\
\hline & $>360$ & 27 & \\
\hline \multirow{4}{*}{$\beta=10^{\circ} \mathrm{C} / \mathrm{min}$} & $120-220$ & 5.46 & \multirow{4}{*}{296.23} \\
\hline & $220-310$ & 45.05 & \\
\hline & $310-410$ & 13.86 & \\
\hline & $>365$ & 26.69 & \\
\hline \multirow{4}{*}{$\beta=15^{\circ} \mathrm{C} / \mathrm{min}$} & $135-225$ & 5.86 & \multirow{4}{*}{301.37} \\
\hline & $225-315$ & 46.63 & \\
\hline & $315-372$ & 15.84 & \\
\hline & $>372$ & 25.5 & \\
\hline \multirow{4}{*}{$\beta=20^{\circ} \mathrm{C} / \mathrm{min}$} & $140-230$ & 5.98 & \multirow{4}{*}{306.52} \\
\hline & $230-320$ & 43.82 & \\
\hline & $320-380$ & 18.59 & \\
\hline & $>380$ & 24.7 & \\
\hline
\end{tabular}

\subsection{Differential thermal analysis and differential scanning calorimetry.}

Figures 4 and 5 show the DTA and DSC curves of raw loquat kernels. The DTA plot of RLK is given in Fig. 4. The DTA, as well as the DSC curve (Figures 4 and 5a), shows, after the dehydration step, that the decomposition of loquat kernels is associated with exothermic heat flows.

Moreover, RLK presents a high temperature of thermal transition (figure 5b); this could be attributed to the higher protein content exhibited in the proximate composition analysis (Table 2) and also to the significant amount of starch $20 \%$ [12].

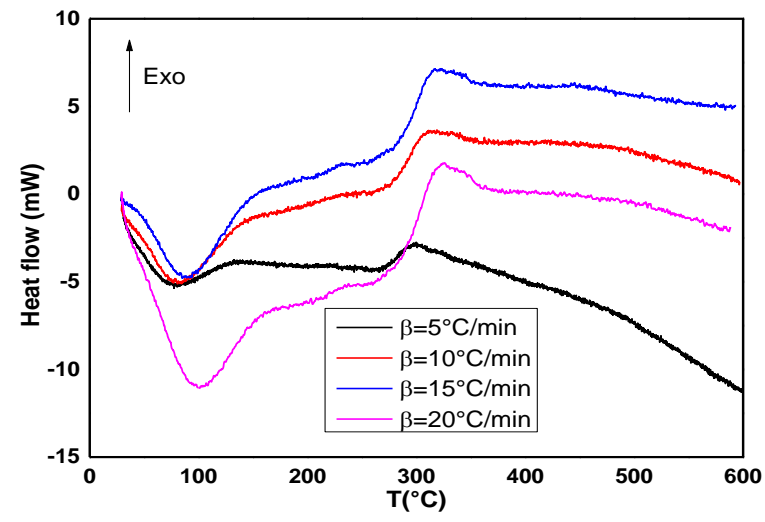

Figure 4. DTA plot of RLK. 
Proteins have a physical barrier role since they form a matrix around the starch granules lowering their water absorption delaying the transition and/or gelatinization process [12].
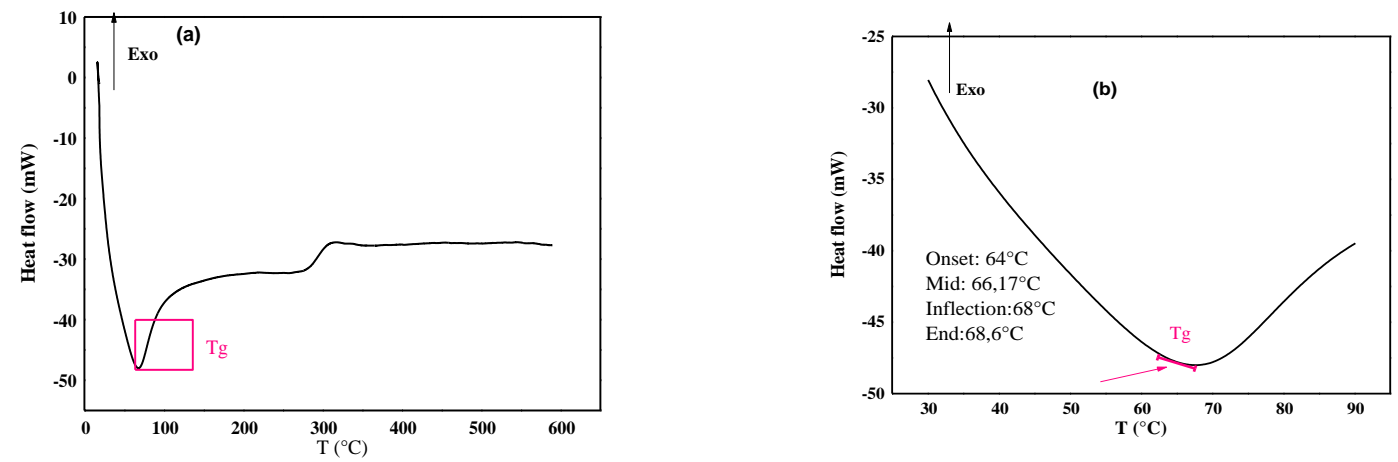

Figure 5. DSC plots of RLK, DSC curve of RLK (a), onset, mid-, and endpoints of the glass transition temperature (b).

A TG study consists of performing a kinetic analysis, which includes weight loss curves obtained at different heating rates to deduce the kinetic parameters' dependence with the conversion. The kinetic parameters such as activation energy and pre-exponential factor were obtained for two degradation steps by isoconversional model-free methods proposed by FWO, KAS, Kissinger, Tang, MKN, and FR. With the assumption that there are no physical limitations and that the degradation of RDS is a global chemical reaction, the degradation mode thus being: $f(\alpha)=(1-\alpha) n$ with $n=1$ for Fr and $g(\alpha)=-\operatorname{Ln}(1-\alpha)$ for the other methods. The isoconversional lines for each conversion rate are shown in figure 6 . The values of activation energy $\mathrm{Ea}$ and pre-exponential factor $\mathrm{A}$ are shown in tables 7 and 8. The dependence of activation energies as a function of conversion rate is shown in figure 7.

Friedman's method has been first employed to analyze the TG data of RLK, which is probably the most general of the derivative techniques. This method is based on the intercomparison of the weight loss rates $\mathrm{d} \alpha / \mathrm{d} t$ with different linear heating rates for a given fractional weight loss. Eq. (9) has been utilized to determine the values of activation energies from $\operatorname{Ln}(\mathrm{d} \alpha / \mathrm{dt})$ plots versus $1 / T$ over a wide range of conversions. The calculated results have been summarized in Table 7. However, the mean values of $E_{a}$ are $190-271 \mathrm{~kJ} / \mathrm{mol}$ for RLK thermal decomposition.

Another derivative method used in this paper is KAS method employed to analyze the TG data of RLK. Eq. (10) has been used to obtain the activation energy, which can be calculated from the plot of $\operatorname{Ln}\left(\beta / T^{2}\right)$ versus $1 / T$ and fitting to a straight line. The results are given in Table 7. The activation energy of the thermal degradation of RLK, $E_{a}$ is $172-242 \mathrm{~kJ} / \mathrm{mol}$.

Flynn-Wall-Ozawa method is an integral method also being independent of the degradation mechanism. Eq. (11) has been used, and the apparent activation energy of RLK can therefore be obtained from a plot of $\ln \beta$ against $1 / T$ for a specific degree of conversion since the slope of such a line is given by $1.052(E a / R T)$. The activation energies calculated from the slopes are recorded in Table 7. The average values of Ea of RLK, are $172-245 \mathrm{~kJ} / \mathrm{mol}$.

Using Eqs. (12) and (13), the $E_{a}$ and the frequency factor A values can be conveniently obtained using the MKN method or Tang method. The calculation results from these two methods are given in Table 8 . Figure 6 presents the plots of $\operatorname{Ln}\left[\beta / T^{1.884318}\right]$ versus $1 / \mathrm{T}$ or $\ln \left[\beta / \mathrm{T}^{1.894661}\right]$ versus $1 / \mathrm{T}$ for the MKN method or Tang method, respectively. As can be seen, the two methods have resulted in linear Arrhenius plots over the two-stage conversion range, and such good linearity has also been reflected by the correlation coefficient presented in Table 
8. It can be seen that the $E_{a}$ values obtained from these two methods are almost identical to each other for each conversion level over the two thermal degradation stages. For the MKN method, the $E_{a}$ value varies from 172 to $221 \mathrm{~kJ} \mathrm{~mol}^{-1}$, similar to the Tang method values.

Figure 7 shows the dependence of activation energy on the conversion degree for $\alpha=0.1$ 0.9 for the first and second decomposition intervals of RLK.

The FWO, KAS, MKN, and Tang methods give similar values of $E_{a}$ in the $\alpha$ range. In contrast, the values achieved by the Friedman method were quite larger than those obtained by integral methods. The differences in calculated $E_{a}$ values can be due to the error of improper integration in FWO, KAS, MKN, and Tang equations. Friedman's method was instantaneous values and so very sensitive to the experimental noises.

The activation energy and pre-exponential factor obtained by the Kissinger method (Figure 9, Table 10) are $173 \mathrm{~kJ} / \mathrm{mol}$ and $1.91 \times 10^{16}$. As for free model methods, the average parameters calculated are $E_{a}: 172-248 \mathrm{~kJ} \mathrm{~mol}^{-1}$ and A: $5,30 \times 10^{20} \mathrm{~min}^{-1}$ for integral methods (FWO, KAS, Tang, and MKN) and Ea:190-271 kJ.mol ${ }^{-1}$ and A: $1.77 \times 10^{22} \mathrm{~min}^{-1}$ for differential Fr method.

The results obtained from the first method represented actual values of kinetic parameters, which are the same for the whole pyrolysis process, while the second method presented apparent values of kinetic parameters because they are the sum of the parameters of the physical processes and chemical reaction that occur simultaneously during pyrolysis. The activation energy decreases in the final stages of the process. The energy required for hemicellulose degradation is lower than that of cellulose.

Table 7. Data from Fr, FWO, and KAS model-free methods.

\begin{tabular}{l|l|l|l|l|l|l|l|l|l}
\multirow{2}{*}{ conversion } & FR & \multicolumn{2}{l|}{ FWO } & \multicolumn{2}{l}{ KAS } \\
\cline { 2 - 10 } & $\mathrm{R}^{2}$ & $\mathrm{E}_{\mathrm{a}}\left(\mathrm{kJ} \cdot \mathrm{mol}^{-1}\right)$ & $\mathrm{A}\left(\mathrm{min}^{-1}\right)$ & $\mathrm{R}^{2}$ & $\mathrm{E}_{\mathrm{a}}\left(\mathrm{kJ} \cdot \mathrm{mol}^{-1}\right)$ & $\mathrm{A}\left(\mathrm{min}^{-1}\right)$ & $\mathrm{R}^{2}$ & $\mathrm{E}_{\mathrm{a}}\left(\mathrm{kJ} \cdot \mathrm{mol}^{-1}\right)$ & $\mathrm{A}\left(\mathrm{min}^{-1}\right)$ \\
\hline 0,1 & 0,99977 & 190,10064 & $6,338.10^{17}$ & 0,99471 & 172,024504 & $2,6113.10^{16}$ & 0,99414 & 172,429592 & $3,0014.10^{16}$ \\
\hline 0,2 & 0,99985 & 189,953886 & $1,9235.10^{17}$ & 0,99881 & 180,92671 & $5,499.10^{16}$ & 0,99868 & 181,367495 & $6,3418.10^{16}$ \\
\hline 0,3 & 0,99996 & 194,516574 & $3,8865.10^{17}$ & 0,99989 & 184,061208 & $6,6948.10^{16}$ & 0,99987 & 184,455076 & $7,6271.10^{16}$ \\
\hline 0,4 & 0,9976 & 190,533591 & $1,3424.10^{17}$ & 0,9999 & 186,451912 & $8,637.10^{16}$ & 0,99989 & 186,830738 & $9,7962.10^{16}$ \\
\hline 0,5 & 0,99943 & 203,952746 & $1,9022.10^{18}$ & 0,99973 & 188,591737 & $1,1179.10^{17}$ & 0,9997 & 188,96591 & $1,2655.10^{17}$ \\
\hline 0,6 & 0,99944 & 209,600138 & $4,5337.10^{18}$ & 0,99969 & 192,251376 & $1,9953.10^{17}$ & 0,99965 & 192,706324 & $2,2945.10^{17}$ \\
\hline 0,7 & 0,99549 & 229,524194 & $1,7589.10^{20}$ & 0,99892 & 201,839473 & $1,1734.10^{18}$ & 0,9988 & 202,667189 & $1,4514.10^{18}$ \\
\hline 0,8 & 0,98336 & 259,37039 & $3,5023.10^{22}$ & 0,99214 & 219,860956 & $3,246.10^{19}$ & 0,99139 & 221,454769 & $4,6143.10^{19}$ \\
\hline 0,9 & 0,95603 & 271,47 & $1,2378.10^{23}$ & 0,97663 & 245,485694 & $2,6592.10^{21}$ & 0,97466 & 248,151059 & $4,4884.10^{21}$
\end{tabular}

RLK has a complex heterogeneous nature; hence, it would be difficult to obtain the same experimental results even for nominally the same sample [55]. Therefore, the same experimental technique, including sample preparation procedure, analysis method adopted, and the kinetic model for the analysis should be employed to enable a reasonable comparison to be achieved.

Table 8. Data from Tang and MKN integral approximation methods.

\begin{tabular}{l|c|c|c|c|c|c}
\multirow{2}{*}{ Conversion } & \multicolumn{5}{|c|}{ Tang } & \multicolumn{3}{c}{ MKN } \\
\cline { 2 - 7 } & $\mathrm{R}^{2}$ & $\mathrm{E}_{\mathrm{a}}\left(\mathrm{kJ} \cdot \mathrm{mol}^{-1}\right)$ & $\mathrm{A}\left(\mathrm{min}^{-1}\right)$ & $\mathrm{R}^{2}$ & $\mathrm{E}_{\mathrm{a}}\left(\mathrm{kJ} . \mathrm{mol}^{-1}\right)$ & $\mathrm{A}\left(\mathrm{min}^{-1}\right)$ \\
\hline 0,1 & 0,99417 & 172,629043 & $3,2858.10^{16}$ & 0,99418 & 172,590866 & $3,2319.10^{16}$ \\
\hline 0,2 & 0,99868 & 181,576407 & $6,9414.10^{16}$ & 0,99869 & 181,536121 & $6,8272.10^{16}$ \\
\hline 0,3 & 0,99987 & 184,670635 & $8,3539.10^{16}$ & 0,99987 & 184,629952 & $8,217.10^{16}$ \\
\hline 0,4 & 0,99989 & 187,050159 & $1,0732.10^{17}$ & 0,99989 & 187,009088 & $1,0557.10^{17}$ \\
\hline 0,5 & 0,9997 & 189,188379 & $1,3866.10^{17}$ & 0,9997 & 189,146869 & $1,3639.10^{17}$ \\
\hline 0,6 & 0,99965 & 192,929102 & $2,5119.10^{17}$ & 0,99965 & 192,886306 & $2,4706.10^{17}$ \\
\hline 0,7 & 0,99881 & 202,882179 & $1,5825.10^{18}$ & 0,99881 & 202,835302 & $1,5559.10^{18}$ \\
\hline 0,8 & 0,99144 & 221,651513 & $4,9928.10^{19}$ & 0,99144 & 221,596682 & $4,9052.10^{19}$ \\
\hline 0,9 & 0,97477 & 248,322915 & $4,8111.10^{21}$ & 0,97478 & 248,256614 & $4,7223.10^{21}$
\end{tabular}



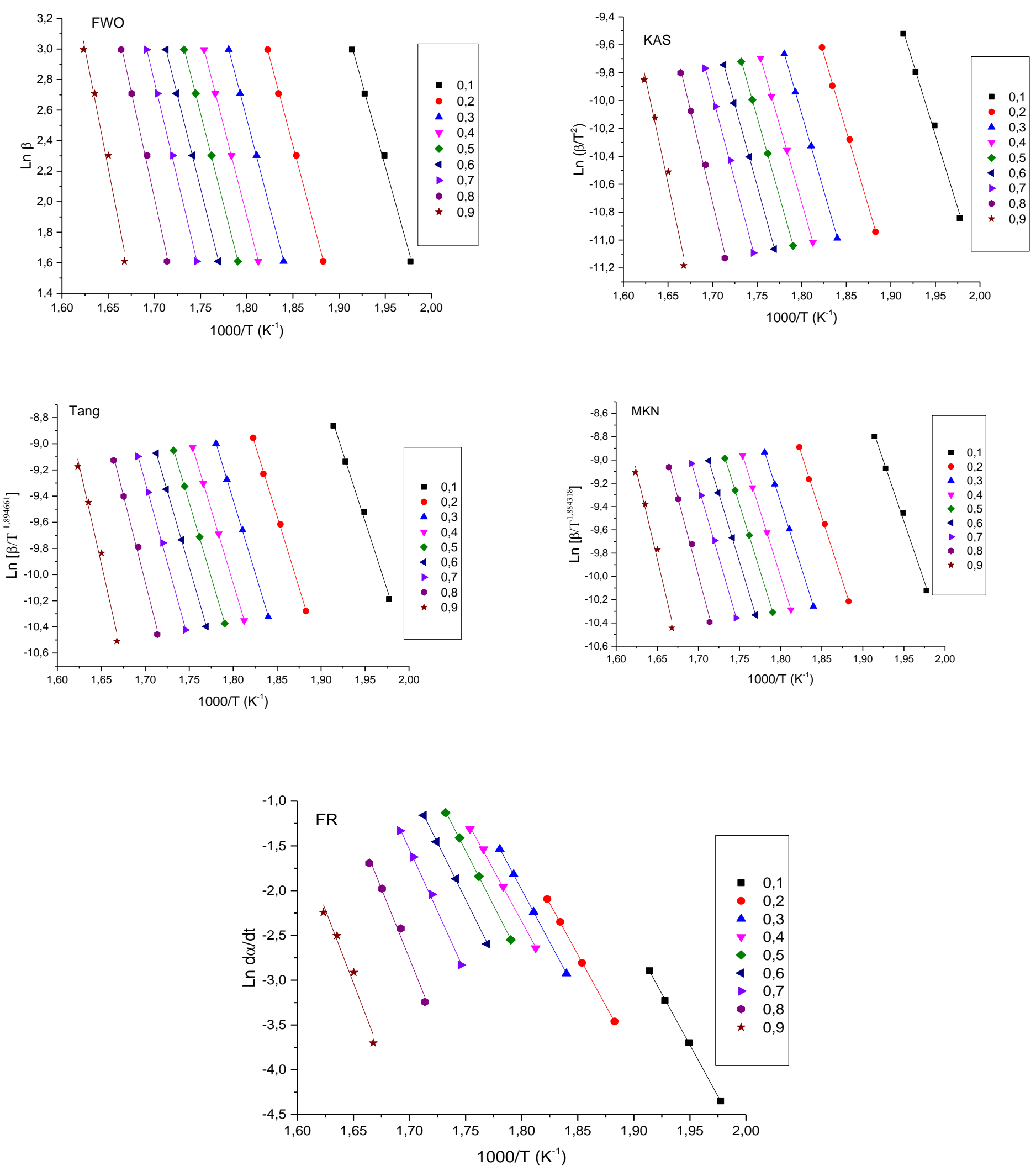

Figure 6. Iso-conversional plots of FWO, KAS, Tang, MKN and FR for RLK at different conversion rates 


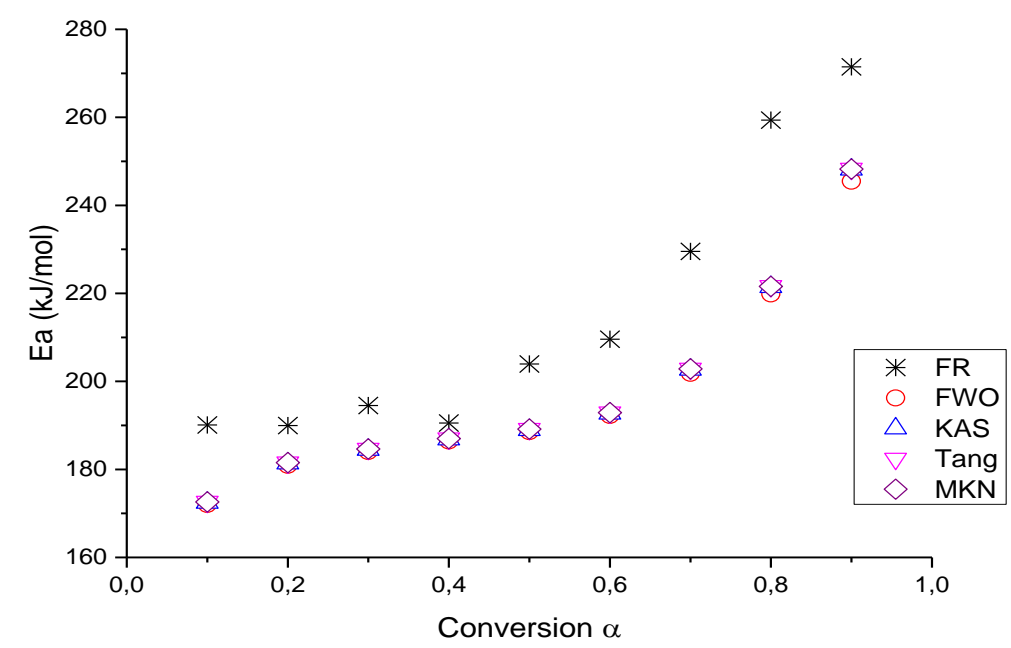

Figure 7. Dependence of activation energy on conversion degree $\alpha$ according to FR, FWO, KAS, MKN, and Tang methods for decomposition of RLK.

\subsection{Determination of the most probable reaction function.}

\subsubsection{Criado method.}

In order to find the kinetic model of thermal degradation, the Criado and Coats-Redfern methods were chosen as they involve the degradation mechanisms. Coats-Redfern method was used. According to Eq. (14), the activation energy for every $g(\alpha)$ function listed in table 1 can be calculated for all heating rates from fitting $\operatorname{Ln}\left(g(\alpha) / T^{2}\right)$ versus $1 / T$ plots. The activation energies and correlations are summarized in Table 9.

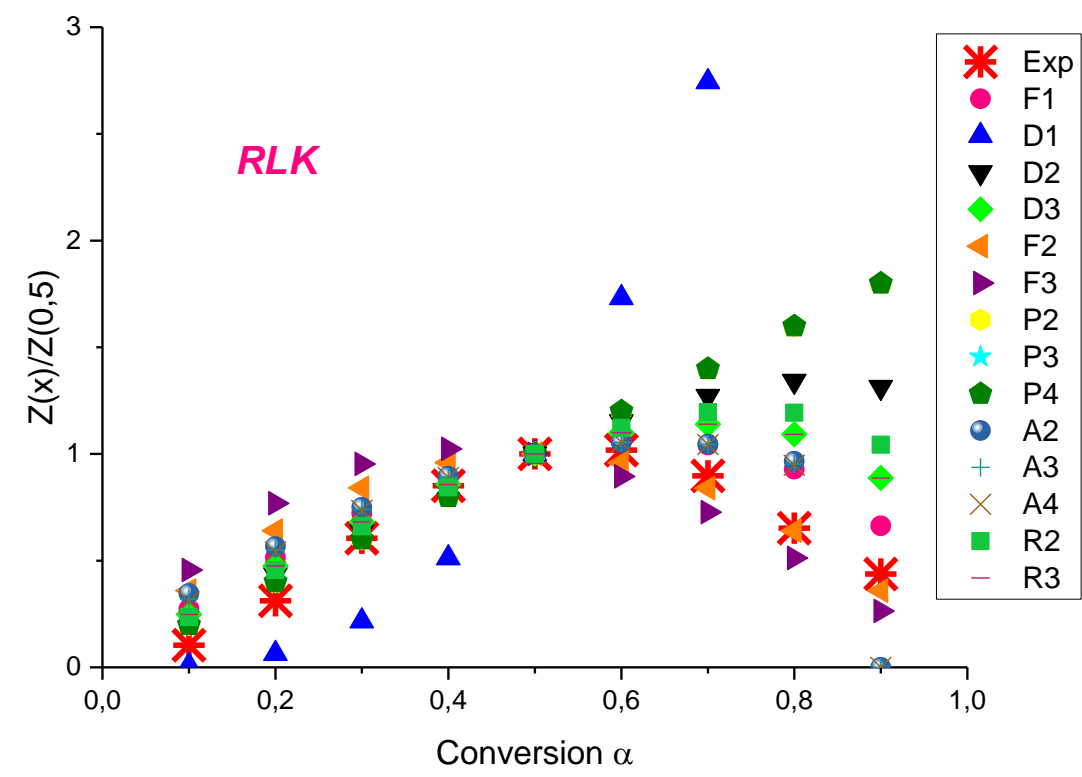

Figure 8. Masterplots of different kinetic models and experimental data at $10 \mathrm{Kmin}-1$ calculated by Eq. (12) for RLK degradation.

According to Coats Redfern equation, if a correct model is selected for the reaction, the plot of $\operatorname{Ln}\left(g(\alpha) / \mathrm{T}^{2}\right)$ versus $1 / \mathrm{T}$ will be linear as possible with a high-correlation coefficient, in this case, reaction order F1. One can say that the Coats Redfern method reliability is not enough 
and cannot be used to kinetics assessment of reactions. From this point of view, using Criado's method is very important; this method gives us more information and can be additional to Coats Redfern's method.

The used models and the expressions of associated functions $g(x)$ and $f(x)$ are shown in Table 1 . The master curve plots $Z(x) / Z(0.5)$ versus $\alpha$ for different mechanisms according to the Criado method for RLK degradation is illustrated in figure 8. As can be seen, the comparison of the experimental master plots with theoretical ones revealed that the reaction order F2 most probably described the kinetic process for the degradation of hemicellulose and cellulose of RLK. Thus, reaction order, order-based models (Fn) are the simplest models as they are similar to those used in homogeneous kinetics. In these models, the reaction rate is proportional to the concentration, amount, or fraction remaining of reactant raised to a particular power, which is the reaction order.

\begin{tabular}{|c|c|c|c|c|c|c|c|c|c|c|c|c|}
\hline \multirow{2}{*}{$\mathrm{DM}$} & \multicolumn{3}{|c|}{$\beta=5^{\circ} \mathrm{C} / \mathrm{min}$} & \multicolumn{3}{|c|}{$\beta=10^{\circ} \mathrm{C} / \mathrm{min}$} & \multicolumn{3}{|c|}{$\beta=15^{\circ} \mathrm{C} / \mathrm{min}$} & \multicolumn{3}{|c|}{$\boldsymbol{\beta}=\mathbf{2 0}^{\circ} \mathrm{C} / \mathrm{min}$} \\
\hline & $E_{a}(\mathrm{~kJ} / \mathrm{mol})$ & $A\left(\min ^{-1}\right)$ & $R^{2}$ & $E_{a}(\mathrm{~kJ} / \mathrm{mol})$ & $A\left(\min ^{-1}\right)$ & $R^{2}$ & $E_{a}(k J / m o l)$ & $A\left(\min ^{-1}\right)$ & $R^{2}$ & $E_{a}(\mathrm{~kJ} / \mathrm{mol})$ & $A\left(\min ^{-1}\right)$ & $R^{2}$ \\
\hline Fo & 54,33 & $5,63.10^{3}$ & 0,9605 & 56,59 & $1,56.10^{4}$ & 0,9714 & 57,81 & $2,68.10^{4}$ & 0,9718 & 58,08 & $3,44.10^{4}$ & 0,9713 \\
\hline F1 & 78,65 & $2,33.10^{6}$ & 0,9885 & 81,41 & $6,59 \cdot 10^{6}$ & 0,9872 & 57,81 & $2,68.10^{4}$ & 0,9718 & 83,58 & $1,54.10^{7}$ & 0,9883 \\
\hline F2 & 112,88 & $9,02.10^{9}$ & 0,9692 & 116,23 & $2,59.10^{10}$ & 0,9585 & 118,66 & $5,06.10^{10}$ & 0,9593 & 119,34 & $6,50.10^{10}$ & 0,9606 \\
\hline D1 & 117,80 & $4,70.10^{9}$ & 0,9668 & 122,45 & $1,76.10^{10}$ & 0,9758 & 124,98 & $3,49 \cdot 10^{10}$ & 0,9761 & 125,58 & $4,36.10^{10}$ & 0,9757 \\
\hline D2 & 131,09 & $5,84.10^{10}$ & 0,9779 & 136,03 & $2,24.10^{11}$ & 0,9838 & 138,85 & $4,56.10^{11}$ & 0,9842 & 139,53 & $5,68.10^{11}$ & 0,9841 \\
\hline D3 & 106,01 & $2,78.10^{7}$ & 0,9601 & 110,28 & $1,00.10^{8}$ & 0,9708 & 112,58 & $1,93.10^{8}$ & 0,9711 & 113,10 & $2,42.10^{8}$ & 0,9705 \\
\hline D4 & 187,10 & $8,04.10^{15}$ & 0,9874 & 193,11 & $3,23.10^{16}$ & 0,9829 & 197,08 & $7,44.10^{16}$ & 0,9835 & 198,17 & $9,25.10^{16}$ & 0,9842 \\
\hline A1 & 12,80 & $3,53 \cdot 10^{-1}$ & 0,9741 & 13,41 & $7,85.10^{-1}$ & 0,9733 & 13,77 & 1,24 & 0,9749 & 13,83 & 1,64 & 0,9758 \\
\hline A2 & 34,75 & $9,81.10^{1}$ & 0,9855 & 36,08 & $2,35.10^{2}$ & 0,9842 & 36,89 & $3,89.10^{2}$ & 0,9851 & 37,08 & $5,06.10^{2}$ & 0,9856 \\
\hline A3 & 20,12 & 2,59 & 0,9811 & 20,97 & 5,90 & 0,9799 & 21,48 & 9,48 & 0,981 & 21,58 & $1,24.10^{1}$ & 0,9817 \\
\hline $\mathbf{R 2}$ & 73,76 & $2,95.10^{5}$ & 0,9735 & 76,74 & $8,92.10^{5}$ & 0,9831 & 78,37 & $1,60.10^{6}$ & 0,9833 & 78,72 & $2,03.10^{6}$ & 0,9823 \\
\hline $\mathbf{R 3}$ & 65,28 & $4,35.10^{4}$ & 0,981 & 67,79 & $1,22.10^{5}$ & 0,9856 & 69,24 & $2,15.10^{5}$ & 0,9862 & 69,58 & $2,76.10^{5}$ & 0,9862 \\
\hline R4 & 61,38 & $2,20.10^{4}$ & 0,9755 & 63,80 & $9,64.10^{4}$ & 0,9822 & 65,17 & $1,07.10^{5}$ & 0,9827 & 65,48 & $1,38.10^{5}$ & 0,9826 \\
\hline $\mathbf{P 2}$ & 22,59 & 3,77 & 0,9421 & 23,67 & 8,99 & 0,9583 & 24,23 & $1,45.10^{1}$ & 0,9591 & 24,33 & $1,89.10^{1}$ & 0,9583 \\
\hline P3 & 12,01 & $2,35 \cdot 10^{-1}$ & 0,9091 & 12,69 & $5,37.10^{-1}$ & 0,935 & 13,04 & $8,49 \cdot 10^{-1}$ & 0,9366 & 13,08 & 1,11 & 0,9352 \\
\hline P4 & 6,72 & $4,51.10^{-2}$ & 0,8433 & 7,21 & $1,02.10^{-1}$ & 0,8885 & 7,44 & $1,60.10^{-1}$ & 0,8922 & 7,46 & $2,09.10^{-1}$ & 0,8897 \\
\hline
\end{tabular}

\subsection{Thermodynamic parameters.}

As shown in Table 10, the positive change in Gibbs free energy, $\Delta \mathrm{G}^{\#}$, reflects that the system's total energy increases over the whole thermal degradation, mainly by means of heatabsorbing. According to thermodynamic definitions, it can be deduced that the degradation reaction is a non-spontaneous process. Furthermore, it is well known that the magnitude of $\Delta G^{\#}$, measures how far a reaction is from equilibrium, and then, the larger the value of $\Delta G^{\#}$, the further the reaction is from equilibrium and the further the reaction must shift to reach equilibrium. Table 10 also shows that the averaged, $\Delta \mathrm{H}^{\#}$, value for the decomposition of RLK, indicating how large the energy difference between the activated complex and the reagent is. The $\Delta \mathrm{H}^{\#}$, value is positive, and it means that the involved reaction is a thermodynamically unfavorable endothermic process.

Moreover, the values of $\Delta \mathrm{S}^{\#}$ for RLK is positive. It means that the activated complexes were with a lower degree of the arrangement, higher entropy than the initial state. Thus, the large $\Delta S^{\#}$ value suggests that it is far from the system from the initial equilibrium state to the final thermodynamic equilibrium state. Similar observations have also been reported elsewhere for pure chitosan $[37,56-58]$. 


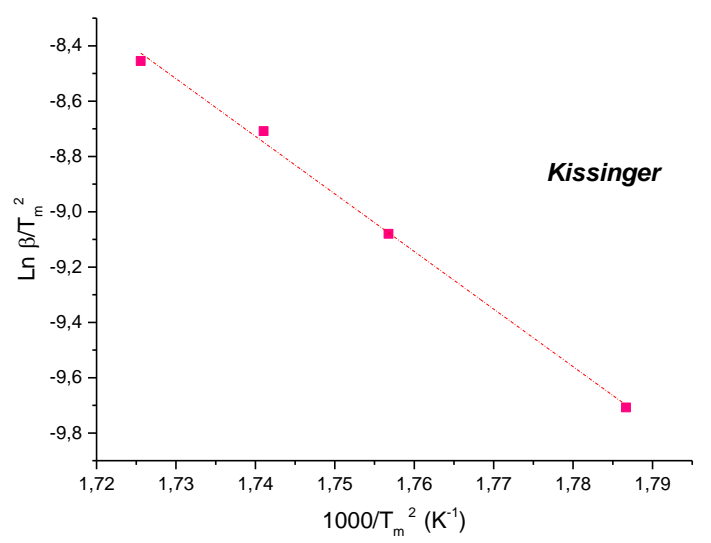

Fig. 9. Kissinger's plots of $\operatorname{Ln}\left(\beta / \mathrm{T}^{2}\right)$ versus $1 / \mathrm{T}$ for the first and second stages of thermal degradation of RLK

Table 10. Thermodynamic parameters of $\Delta \mathrm{S}^{\#}, \Delta \mathrm{H}^{\#,}$ and $\Delta \mathrm{G}^{\#}$ calculated for thermal degradation of RLK.

\begin{tabular}{|c|c|}
\hline $\mathbf{R}^{2}$ & 0,99579 \\
\hline Intercept & 27,50752 \\
\hline Slope & $-20,82453$ \\
\hline $\mathrm{Ea}\left(\mathrm{kJ} \cdot \mathrm{mol}^{-1}\right)$ & 173,05 \\
\hline $\mathrm{A}\left(\mathrm{min}^{-1}\right)$ & $1,9118.10^{16}$ \\
\hline Averagea $T_{p}(K)$ & 570,705 \\
\hline$\Delta \mathbf{H}^{\#}\left(\mathbf{K j}_{\mathbf{j}} \mathbf{m o l}^{-1}\right)$ & 168,307003 \\
\hline$\Delta S^{\#}\left(\mathrm{j} . \mathrm{mol}^{-1}\right)$ & 19,0331285 \\
\hline$\Delta G^{\#}\left(K_{j} . m^{-1}{ }^{-1}\right)$ & 157,444701 \\
\hline
\end{tabular}

\subsection{Lifetime prediction.}

From Kissinger's plots of the apparent activation energy Ep for RLK was 172,05.

Then, the pre-exponential factor Ap can be obtained by Eq. (21), and it is slightly affected by the heating rate.
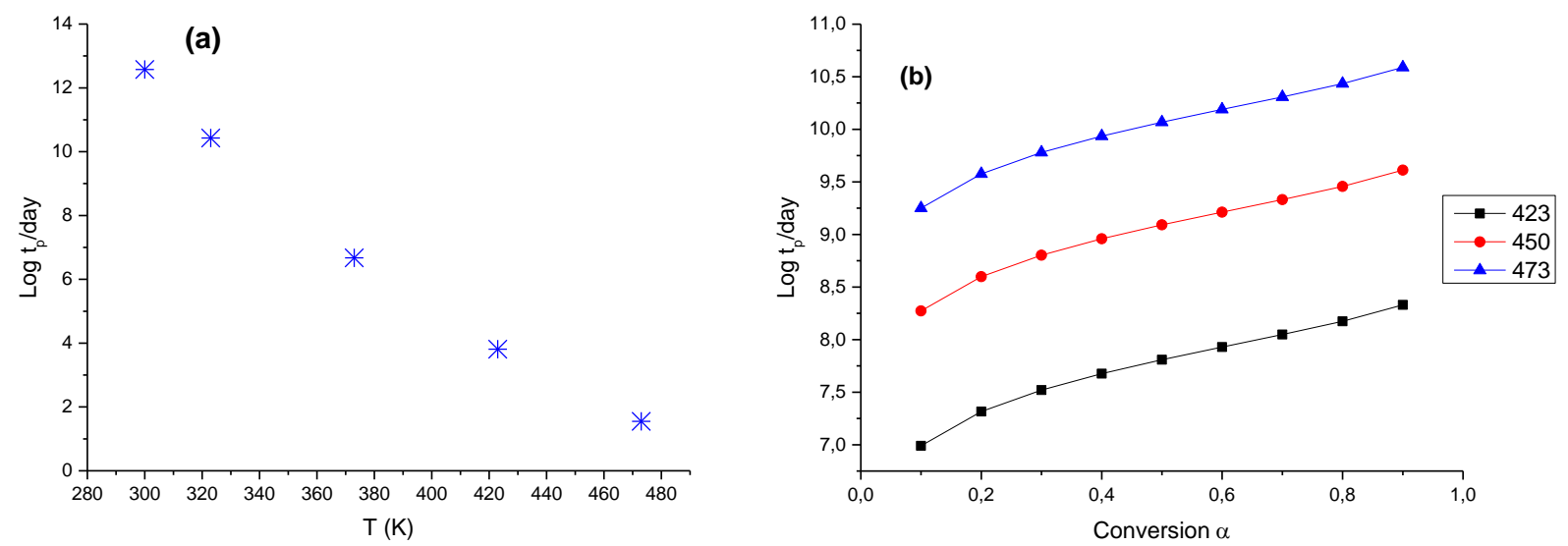

Figure 10. Dependence of the lifetime on the temperature at $5 \%$ conversion (a) and on mass conversion at 423,450 , and $473^{\circ} \mathrm{k}$ for RLK (b)

The $A_{p}$ value averaged over multiple heating rates is $5.00906 \times 10^{15} \mathrm{~min}^{-1}$ for RLK decomposition. The values of Ep and Ln $A_{p}$ should be substituted into Eq. (20) for lifetime predictions as $5 \%$ mass conversion occurs in the first stage of thermal degradation. The 
predicted results are shown in Fig. 10, along with the first-order reaction assumption. Figure 10 shows that the lifetime is strongly dependent on the environmental temperature and decreases exponentially with the temperature increase.

On the other hand, the lifespan is observed to exponentially increase with the RLK mass conversion under isothermal conditions, as shown in Fig. 10. Similar ascertainment was reported by several authors [37, 56-58]. According to such predictions, it may be interestingly estimated that RLK requires < 1 day for $5 \%$ mass loss at 423,450 , and $473 \mathrm{~K}$. Therefore, the life period prediction is much more meaningful since it provides very interesting information about the thermal stability of biomass materials.

\section{Conclusions}

Loquat kernels were subjected to thermo-gravimetric analyzes under an inert atmosphere from room temperature to $600{ }^{\circ} \mathrm{C}$ at four heating rates $\left(5,10,15\right.$, and $\left.20{ }^{\circ} \mathrm{C} / \mathrm{min}\right)$. TGA/DTG has enabled us to study the thermal profile of loquat kernels. Thus, the degradation of the major components occurs essentially between 130 and $410{ }^{\circ} \mathrm{C}$. This degradation is associated with exothermic flow rates, a phenomenon detected by differential thermal analysis and differential scanning calorimetry. The kinetics of thermal degradation of RLK was accurately determined from a series of experiments at four heating rates $(5,10,15$, and 20 ${ }^{\circ} \mathrm{C} / \mathrm{min}$ ). The activation energy was calculated by the isoconversional methods without previous assumptions regarding the conversion model fulfilled by the reaction.

The activation energy and pre-exponential factor obtained by the Kissinger method are $173 \mathrm{~kJ} / \mathrm{mol}$ and $1.91 \times 10^{16}$. Concerning the kinetic parameters calculated from free model methods, the average activation energies $E_{a}$ are running from 172 to $248 \mathrm{~kJ}^{\mathrm{mol}}{ }^{-1}$, and the average pre-exponential factor $\mathrm{A}$ is $5,30 \times 10^{20} \mathrm{~min}^{-1}$ for integral methods (KAS, FWO, MKN,

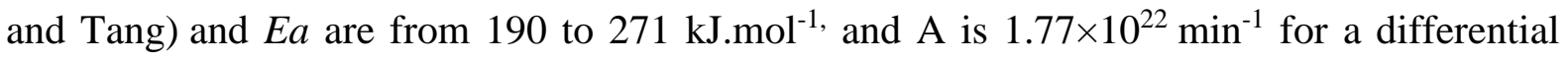
method of Friedman (Fr).

The results obtained from the first method represented actual values of kinetic parameters, which are the same for the whole pyrolysis process, while the second method presented apparent values of kinetic parameters because they are the sum of the parameters of the physical processes and chemical reaction that occur simultaneously during pyrolysis. The activation energy decreases in the final stages of the process. The energy required for hemicellulose degradation is lower than that of cellulose.

Finally, Coats-Redfern and Criado methods were successfully utilized to predict the reaction mechanism of thermal degradation of RLK. Thus, the second-order reaction model (F2) was found to have the best mathematical fit for RLK decomposition.

Based on Arrhenius parameter values, obtained by Kissinger equation, the changes in entropy, enthalpy and Gibbs free energy, and lifetime predictions have been estimated concerning the thermal degradation processes of RLK. Results indicate that the positive change in Gibbs free energy, $\Delta G^{\#}$, reflects that the system's total energy increases over the whole thermal degradation. Additionally, the $\Delta \mathrm{H}^{\#}$, value is positive, and it means that the involved reaction is a thermodynamically unfavorable endothermic process. Moreover, the values of $\Delta \mathrm{S}^{\#}$ is positive. It means that the activated complexes were with a lower degree of the arrangement, higher entropy than the initial state. Lifetime predictions, Log $t_{p} /$ day, have also been investigated. Results show that RLK requires $<1$ day for $5 \%$ mass loss at 423,450 , and $473 \mathrm{~K}$. 


\section{Funding}

This research received no external funding.

\section{Acknowledgments}

This research has no acknowledgment.

\section{Conflicts of Interest}

The authors declare no conflict of interest.

\section{References}

1. Martinez-Calvo, J.; Badenes, M.L.; Llacer, G.; Bleiholder, H.; Hack, H.; Meier, U. Phenological growth stages of loquat tree (Eriobotrya japonica (Thunb.) Lindl.). Ann. Appl. Biol. 1999, 134, 353-357, https://doi.org/10.1111/j.1744-7348.1999.tb05276.x.

2. Gisbert, A.D.; Romero, C.; Martinez-Calvo, J.; Leida, C.; Llacer, G.; Badenes, M.L. Genetic diversity evaluation of a loquat (Eriobotrya japonica (Thunb) Lindl) germplasm collection by SSRs and S-allele fragments. Euphytica 2009, 168, 121-134, https://doi.org/10.1007/s10681-009-9901-z.

3. Caballero, P.; Fernández, M.A. Loquat, production and market. In: First international symposium on loquat, Badenes, M.L., Llácer, G., Eds. Zaragoza : CIHEAM: Volume 58, 2003; pp. 11-20.

4. Directives stratégiques pour la filière phoénicicole, Direction de la Stratégie et des Statistiques, Département de $\quad$ l'Agriculture $2019 . \quad$ http://www.agriculture.gov.ma/sites/default/files/140718dir_strat_palmier_dattier_vdef-sl.pdf

5. Pareek, S.; Benkeblia, N.; Janick, J.; Cao, S.; Elhadi, M.Y. Postharvest physiology and technology of loquat (Eriobotrya japonica Lindl.) fruit. J. Sci. Food Agric. 2014, https://doi.org/10.1002/jsfa.6560.

6. Sütcü, H.; Demiral, H. Production of granular activated carbons from loquat stones by chemical activation. Journal of Analytical and Applied Pyrolysis 2009, 84, 47-52, https://doi.org/10.1016/j.jaap.2008.10.008.

7. Hamdaoui, O. Intensification of the sorption of Rhodamine B from aqueous phase by loquat seeds using ultrasound. Desalination 2011, 271, 279-286,https://doi.org/10.1016/j.desal.2010.12.043.

8. Handan, U.C.U.N. Equilibrium, thermodynamic and kinetics of reactive black 5 biosorption on loquat (Eriobotrya japonica) seed. Sci. Res. Essays. 2011, 6, 4113-4124, https://doi.org/10.5897/SRE11.674.

9. Taskin, M.; Erdal, S. Utilization of waste loquat (Eriobotrya japonica Lindl.) kernel extract for a new cheap substrate for fungal fermentations. Romanian Biotechnological Letters 2011, 16.

10. Zhao, C.; Yan, H.; Liu, Y.; Huang, Y.; Zhang, R.; Chen C.; Liu, G. Bio-energy conversion performance, biodegradability, and kinetic analysis of different fruit residues during discontinuous anaerobic digestion. Waste Manage 2016, 52, 295-301, https://doi.org/10.1016/j.wasman.2016.03.028.

11. He, X.-Y.; Wu, L.-J.; Wang, W.-X.; Xie, P.-J.; Chen, Y.-H.; Wang, F. Amygdalin - A pharmacological and toxicological review. Journal of Ethnopharmacology 2020, 254, https://doi.org/10.1016/j.jep.2020.112717.

12. Turola Barbi, R.C.; Teixeira, G.L.; Hornung, P.S.; Âvila, S.; Hoffmann-Ribani, R. Eriobotrya japonica seed as a new source of starch: Assessment of phenolic compounds, antioxidant activity, thermal, rheological and morphological properties. Food Hydrocolloids https://doi.org/10.1016/j.foodhyd.2017.11.006.

13. El-Sayed, S.A.; Mostafa, M.E. Thermal pyrolysis and kinetic parameter determination of mango leaves using common and new proposed parallel kinetic models. RSC Advances 2020, 10, 18160-18179, https://doi.org/10.1039/d0ra00493f.

14. Rego, F.; Soares Dias, A.P.; Casquilho, M.; Rosa, F.C.; Rodrigues, A. Pyrolysis kinetics of short rotation coppice poplar biomass. Energy 2020, 207, https://doi.org/10.1016/j.energy.2020.118191.

15. Xiao, R.; Yang, W.; Cong, X.; Dong, K.; Xu, J.; Wang, D.; Yang, X. Thermogravimetric analysis and reaction kinetics of lignocellulosic biomass pyrolysis. Energy 2020, 201, https://doi.org/10.1016/j.energy.2020.117537.

16. Nazimudheen, G.; Sekhar, N.C.; Sunny, A.; Kallingal, A.; B, H. Physiochemical characterization and thermal kinetics of lignin recovered from sustainable agrowaste for bioenergy applications. International Journal of Hydrogen Energy 2020, https://doi.org/10.1016/j.ijhydene.2020.03.172.

17. Brown, M.E. Introduction to Thermal Analysis: Techniques and Applications. 2nd Ed. New York Springer 2001.

18. Manyà, J.J.; Velo, E.; Puigjaner, L. Kinetics of Biomass Pyrolysis: a Reformulated Three-Parallel-Reactions Model. Industrial \& Engineering Chemistry Research 2003, 42, 434-441, https://doi.org/10.1021/ie020218p. 
19. Friedman, H.L. Kinetics of thermal degradation of char-forming plastics from thermogravimetry. Application to a phenolic plastic. Journal of Polymer Science Part C: Polymer Symposia 1964, 6, 183-195, https://doi.org/10.1002/polc.5070060121.

20. Flynn, J.H.; Wall, L.A. General treatment of thermogravimetry of polymers. J. Res. Natl. Bur. Stand. Sect. A. 1966, 70A, 487-523, https://doi.org/10.6028/jres.070A.043.

21. Ozawa, T. A new method of analyzing thermogravimetric data. Bull. Chem. Soc. Jpn. 1965, 38, 1881-1886, https://doi.org/10.1246/bcsj.38.1881.

22. Kissinger, H.E. Variation of peak temperature with heating rate in differential thermal analysis. J. Res. Natl. Bur. Stand. 1956, 57, 217-221, http://dx.doi.org/10.6028/jres.057.026.

23. Akahira, T.; Sunose, T. Joint convention of four electrical institutes. Sciences Technology 1971, 16, $22-31$.

24. Coats, A.W.; Redfern, J.P. Kinetic parameters from the thermogravimetric data. Nature, London 1964, 201, 68-69, https://doi.org/10.1038/201068a0.

25. Madhusudanan, P.M.; Krishnan, K.; Ninan, K.N. New equations for kinetic analysis of non-isothermal reactions. Thermochimica Acta 1993, 221, 13-21, https://doi.org/10.1016/0040-6031(93)80519-G.

26. Tang, W.; Liu, Y.; Zhang, H.; Wang, C. New approximate formula for Arrhenius temperature integral. Thermochimica Acta 2003, 408, 39-43, https://doi.org/10.1016/S0040-6031(03)00310-1.

27. AOAC Official methods of analysis of AOAC international, Virginia. 16th ed.; Volume 2. 1995.

28. AOAC Official Methods of Analyses. Washington, DC: Association of Official Analytical Chemist. 1997.

29. AOAC Official methods of analysis. 17th ed. Washington, DC: Associate of Official Analytical Chemist. 2000.

30. Egan, H.; Kirk, R.S.; Sawyer, R. Pearson's chemical analysis of foods. Ed. 8. Edinburgh, London, Melbourne and New York Churchill Livingstone. 1981.

31. Demirbas, A. Calculation of higher heating values of biomass fuels. Fuel 1997, 76, 431-434, https://doi.org/10.1016/S0016-2361(97)85520-2.

32. Plazanet, I.; Zerrouki, R.; Montplaisir, D.; Gady, C.; Boens, B.; Costa G. Effect of ionic liquids on dissolution and identification of wood polysaccharides. Ann Glycomics Lipidomics AGL-101 2018.

33. Zhang, L.; Xie, W.; Zhao, X.; Liu, Y.; Gao, W. Study on the morphology, crystalline structure and thermal properties of yellow ginger starch acetates with different degrees of substitution. Thermochimica Acta 2009, 495, 57-62, https://doi.org/10.1016/j.tca.2009.05.019.

34. Brown, M.E.; Maciejewski, M.; Vyazovkin, S.; Nomen, R.; Sempere, J.; Burnham, A.; Opfermann, J.; Strey, R.; Anderson, H.L.; Kemmler, A.; Keuleers, R.; Janssens, J.; Desseyn, H.O.; Li, C.-R.; Tang, T.B.; Roduit, B.; Malek, J.; Mitsuhashi, T. Computational aspects of kinetic analysis: Part A: The ICTAC kinetics projectdata, methods and results. Thermochimica Acta 2000, 355, 125-143, https://doi.org/10.1016/S00406031(00)00443-3.

35. Criado, J.M. Kinetic analysis of DTG data from master curves. Thermochimica Acta 1978, 24, 186-189, https://doi.org/10.1016/0040-6031(78)85151-X.

36. Rooney, J.J. Eyring transition-state theory and kinetics in catalysis. Journal of Molecular Catalysis A: Chemical 1995, 96, L1-L3, https://doi.org/10.1016/1381-1169(94)00054-9.

37. Lyubomir, T.V.; Velyana, G.G.; Mariana P.T. On the Kinetic Mechanism of Non-isothermal, Degradation of Solids, Atul Tiwari and Baldev Raj. In: Reactions and Mechanisms in Thermal Analysis of Advanced Materials. 2015; pp. 547-578, https://doi.org/10.1002/9781119117711.ch22.

38. Determination of Reaction Kinetics of Straw and Stalk of Rapeseed Using Thermogravimetric Analysis. Energy Sources 2001, 23, 767-774, https://doi.org/10.1080/009083101316862525.

39. Şensöz, S.; Can, M. Pyrolysis of Pine ( Pinus Brutia Ten.) Chips: 1. Effect of Pyrolysis Temperature and Heating Rate on the Product Yields. Energy Sources 2002, 24, 347-355, https://doi.org/10.1080/00908310252888727.

40. Kastanaki, E.; Vamvuka, D. A comparative reactivity and kinetic study on the combustion of coal-biomass char blends. Fuel 2006, 85, 1186-1193, https://doi.org/10.1016/j.fuel.2005.11.004.

41. Rocca, P.A.D.; Cerrella, E.G.; Bonelli, P.R.; Cukierman, A.L. Pyrolysis of hardwoods residues: on kinetics and chars characterization. Biomass and Bioenergy 1999, 16, 79-88, https://doi.org/10.1016/S09619534(98)00067-1.

42. Pietrzak, R. Sawdust pellets from coniferous species as adsorbents for NO2 removal. Bioresource Technology 2010, 101, 907-913, https://doi.org/10.1016/j.biortech.2009.09.017.

43. Sun, X.; Wei, X.; Zhang, J.; Ge, Q.; Liang, Y.; Ju, Y.; Zhang, A.; Ma, T.; Fang, Y. Biomass estimation and physicochemical characterization of winter vine prunings in the Chinese and global grape and wine industries. Waste Management 2020, 104, 119-129, https://doi.org/10.1016/j.wasman.2020.01.018.

44. Singh, S.; Chakraborty, J.P.; Mondal, M.K. Pyrolysis of torrefied biomass: Optimization of process parameters using response surface methodology, characterization, and comparison of properties of pyrolysis oil from raw biomass. Journal of Cleaner Production 2020, 272, https://doi.org/10.1016/j.jclepro.2020.122517.

45. El Hamdaoui, L.; Es-said, A.; El Marouani, M.; El Bouchti, M.; Bchitou, R.; Kifani-Sahban, F.; El Moussaouiti, M. Tosylation Optimization, Characterization and Pyrolysis Kinetics of Cellulose Tosylate. ChemistrySelect 2020, 5, 7695-7703, https://doi.org/10.1002/slct.202001906. 
46. Wang, G.; Fan, B.; Chen, H.; Li, Y. Understanding the pyrolysis behavior of agriculture, forest and aquatic biomass: Products distribution and characterization. Journal of the Energy Institute 2020, 93, 1892-1900, https://doi.org/10.1016/j.joei.2020.04.004.

47. Kauman, W.G. Le matériau bois-propriétés technologie. Mise en æuvre. Association pour la recherche sur le bois en Lorraine 1983.

48. Khiari, B.; Abed, I.; Jeguirim, M.; Zagrouba, F. Thermal conversion of date stones and palm stalks: experimental and kinetic study. Proceeding of the 11th international conference of environmental sciences and technology, Chania, Crete, Greece 2009; B-448-B455.

49. Carrier, M.; Loppinet-Serani, A.; Denux, D.; Lasnier, J.-M.; Ham-Pichavant, F.; Cansell, F.; Aymonier, C. Thermogravimetric analysis as a new method to determine the lignocellulosic composition of biomass. Biomass and Bioenergy 2011, 35, 298-307, https://doi.org/10.1016/j.biombioe.2010.08.067.

50. Shah, M.A.; Khan, M.N.S.; Kumar, V. Biomass residue characterization for their potential application as biofuels. Journal of Thermal Analysis and Calorimetry 2018, 134, 2137-2145, https://doi.org/10.1007/s10973-018-7560-9.

51. Nakanishi, M.; Ogi, T.; Endo, Y.; Otaka, M. Effect of carbonization temperature on composition of carbonized woody biomass. Journal of Thermal Analysis and Calorimetry 2017, 130, 1117-1123, https://doi.org/10.1007/s10973-017-6484-0.

52. Cruz, G.; Santiago, P.A.; Braz, C.E.M.; Seleghim, P.; Crnkovic, P.M. Investigation into the physicalchemical properties of chemically pretreated sugarcane bagasse. Journal of Thermal Analysis and Calorimetry 2018, 132, 1039-1053, https://doi.org/10.1007/s10973-018-7041-1.

53. Kifani-Sahban, F.; Kifani, A.; Belkbir, L.; Belkbir, A.; Zoulalian, A.; Arauzo, J.; Cardero, T. A physical approach in the understanding of the phenomena accompanying the thermal treatment of lignin. Thermochimica Acta 1997, 298, 199-204, https://doi.org/10.1016/S0040-6031(97)00115-9.

54. Antal, M.J.Jr. Chapter 4-Biomass pyrolysis: a review of the literature Part 2: lignocellulose pyrolysis. In: Advances in solar energy. Duffie, J.A.; Boer, K.W. editors. New York, Plenum Volume 3, 1984; pp. 175255.

55. Lopes Grotto, C.G.; Gomes Colares, C.J.; Lima, D.R.; Pereira, D.H.; Teixeira do Vale, A. Energy potential of biomass from two types of genetically improved rice husks in Brazil: A theoretical-experimental study. Biomass and Bioenergy 2020, 142, https://doi.org/10.1016/j.biombioe.2020.105816.

56. Georgieva, V.; Zvezdova, D.; Vlaev, L. Non-isothermal kinetics of thermal degradation of chitosan. Chemistry Central Journal 2012, 6, https://doi.org/10.1186/1752-153X-6-81.

57. Yu-Hua, H.; Xing-Yue, F.; Zhen, H.; Ya-Li, L.; Qiao-Qiao, Y.; Yu-Wen, P.; Jing-Wen, W.; Xin-Yu, Y. A comparison study on non-isothermal decomposition kinetics of chitosan with different analysis methods.J. Therm. Anal. Calorim. 2017, 128, 1077-1091. https://doi.org/10.1007/s10973-016-5972-y

58. Taboada, E.; Cabrera, G.; Jimenez, R.; Cardenas, G. A kinetic study of the thermal degradation of chitosanmetal complexes. J. Appl. Polym. Sci. 2009, 114, 2043-52, https://doi.org/10.1002/app.30796. 